\title{
A Virtual Environment Based on DAISY Technology for Developing EFL Reading Comprehension Skills of Preparatory Stage Visually- Impaired Pupils and Reducing their Cognitive Load
}

\author{
Ast. Prof. Amin Salah Eldin \\ Ast. Professor, Educational Technology Dept. \\ Faculty of Education, Mansoura University
}

\author{
Dr. Samah Rizk R. Hassan
}

Lecturer, Curriculum \& Instruction, (TEFL)

Faculty of Education, Mansoura University

\begin{abstract}
:
The current study aimed at investigating the effectiveness of using a proposed virtual environment based on DAISY technology for developing EFL reading comprehension skills of preparatory stage visually- impaired pupils and reducing their cognitive load while reading. Based on the literature review, related studies and content specification of first year prep, seven EFL reading comprehension sub-skills were determined. Two intact groups were assigned as experimental studying reading through the proposed E- environment; and the other as control studying through the traditional method. Instruments of the study included: a reading comprehension test, and a cognitive load scale for measuring those pupils' cognitive load level before and after the experiment. The content of the units was taught to pupils through the proposed virtual environment. Results revealed that the proposed virtual environment had a great effect on enhancing the pupils' EFL reading skills and reducing their cognitive load while reading as there were statistically significant differences between each of the pre- and postadministrations of both the reading comprehension test and the cognitive load scale. The study also proposed some recommendations and suggestions for further research.
\end{abstract}

Key Words: DAISY Technology, EFL Reading comprehension skills, Cognitive load, the Visually-Impaired

\section{Introduction:}

Learning a foreign language is important for everybody, particularly if the person's native language is not very widespread, and it is a demand for communication in modern world; including the use of the world wide web (Christidou, 2016). Foreign language learning is even more important for visually impaired (VI) persons, as it can be the path out of isolation as it might serve as the vehicle that will enable them to participate in various formal and informal learning activities and other international events in order to decrease the gap caused by sight loss or by severe visual impairment and increase recreational opportunities. Mastering a foreign language, particularly English, thus becomes a sort of "bridge" by means of which the visually- impaired person can access 
different cultures and different prospects in the field of social contacts (Shoeir, 2009; Quatraro, 2011).

Reading skills are essential for academic achievement, personal development, and participation in daily activities for all students, including students with visual impairments (Kelly, 2011). Reading is one of the essential skills that needs to be acquired early in life. It involves two types of processes; micro or low-level process of decoding words and macro process corresponding to understanding of text (Gonzalez Garcia, 2004). Vision, is one of the many factors that influence the ability to develop reading skills. Any defect in the visual system could impede reading process and consequently affect reading performance. Visuallyimpaired children will experience degraded visual input and need more time and effort for word recognition when reading. As a result, less processing capacity and working memory is left for understanding the text (Gompel et al., 2004).

The most successful reading tool for the visually- impaired learners is the Braille dot code. Braille was invented by Louis Braille during the twentieth century. It is a tool used by people with visual impairments to gain literacy skills by providing the users a method of both reading and writing. Since its invention, Braille code has undergone various stages in its evolution and so is the educational implementation of Braille instruction and use by school-age children (Ndung'u, 2011). However, Braille is complex to manipulate since a dot or more have multiple meanings depending on the placement of the dots. Moreover, because all the letters of the alphabets are formed from the basic six-dot cell of the Braille, there are so many word contractions which may give rise to fatigue and problems in reading comprehension especially where extensive reading is required. Braille reading therefore, makes more cognitive demand on the readers (Onuigbo\& Eze, 2012).

It is often stated that students first learn to read so that they can later read to learn, but visually- impaired learners are particularly disadvantaged when it comes to working with printed text. While they may readily learn to read, using either braille or magnified print, they may struggle to reach reading rate levels adequate for achieving their true potential as they move through the educational system and on into employment (Jackson\& Presley, 2012). In other words, Braille reading which is slow makes the rate of information processing equally slow (Ayoku, 2006). By the time the reader gets to the end of the text, he/she may have forgotten the initial information. This could also be the reason why Blackorby, Chorost, Garza and Guzman (2003) and Litterick (2006) pointed out that many students with visual impairment experience significant problems in reading comprehension. 
Unfortunately, it is assumed that blind and visually impaired foreign language learners experience more difficulties than sighted learners as they need adaptive and technical accommodations in their learning process. More importantly, their opportunities for implicit foreign language learning are more limited. There are several obstacles connected with the absence of visual information and a necessity for adapted study and testing materials (Lovi, 2013).

One of the main challenges that hugely affect readers' performance is cognitive load. It plays a pivotal role to facilitate readers to learn, memorize, and digest a piece of novel information. However, cognitive load can also have insignificant impacts on reading task when the cognitive demands of the reading task impose solving a complex problem. In reading to learn, cognitive overload is always happening especially when reading task caters to learn novel information that taxing readers' mental resources. Therefore, cognitive overloading is considered one of the main challenges that hinders readers to learn and acquire new knowledge (Ghanimi, Ab Aziz\& Ahmad, 2016).

Cognitive Load Theory (CLT) is a theory of how the human brain learns and stores knowledge. It originated in the 1980s through the work of John Sweller and his colleagues at the University of New South Wales. Like many other educational researchers at the time,
Sweller and his team were interested in a cognitive approach to problem solving (Elliott, Kurz, Beddow\& Frey, 2009). In cognitive psychology, cognitive load theory provides a promising framework for studying cognitive functioning and learning activities. It is one of the prominent theories to explain how reader process and learn new information. It contributes to education and learning by using human cognitive architecture to understand the design of instruction as it assumes limited working memory resources when information is being processed (Sweller \& Chandler, 1994; Sweller, Van Merriënboer \& Paas, 1998; Van Merriënboer \& Sweller, 2005). Furthermore, it demonstrates that instructional methods are most effective when designed to fit within the known limits of working memory, and therefore supports guided models of instruction (Centre for Education, Statistics and Evaluation, 2017).

Cognitive load theory distinguishes three different types of contributions to total cognitive load (Sweller, 2008; Ton, 2010): intrinsic (ICL), extraneous (ECL)and germane cognitive load (GCL). ICL represents inherent complexity of the information being received and mainly results from the degree of complexity of the learning task, learners' level of knowledge and interactions between those two factors; ECL is also called invalid load that is caused by improper instructional design and material used to present the content that's why it is unnecessary and excessive in nature and should be reduced; and finally, GCL refers to learners' effective 
cognition to the learning tasks and their cognitive resources that they can invest in the learning process, so this load type is ideal, does not overload working memory and leads to new information being transferred to long-term memory thus resulting in effective learning. In effect, the three types of cognitive load are assumed to be additive and the sum is called total cognitive load. If the cognitive load requires more working memory recourses than the learners have, it will cause cognitive overload and the learning activities are unable to be carried out effectively and smoothly (Paas et al., 2003; Sweller, 2008;

Sweller,2010Van Merriënboer\& Sweller, 2005).

Both intrinsic and extraneous loads are representing the negative effects on readers, which mean they impose load on readers that hampers their learning performance. In specific, intrinsic load related to the demands of complex reading task. While extraneous load related to the load from the environment such as, 1) time pressure, 2) physical environment, and 3)task presentation3. The negative effect from those two aforementioned concepts (intrinsic and extraneous) called as a mental load. When readers encounter a high level of mental load they become cognitively overloaded and therefore they will not be able to stay focus and continue reading/learning (Ghanimi, $\mathrm{Ab}$ Aziz\& Ahmad, 2016).Therefore, IL should be optimized in instructional design by selecting learning tasks that match learners' prior knowledge, while EL should be minimized to reduce ineffective load and to allow learners to engage in activities imposing GL (Van Merriënboer \& Sweller, 2005; Leppink et al, 2013).

The technological developments during the last few decades have significantly increased access to information in all formats for learners with visual impairments. As Kapperman \& Sticken (2000) observed, the ability to access information is essential for success in education employment and life. Therefore, much of the development of assistive technology has focused on providing access to information. In particular, devices to read and write Braille and print have significantly improved with the application of new technology. Such devices include audio technology (tapes and tape recorder, auditory text, recorded texts and synthetic speech) as well as computer based technology such as Braille embossers (specialized tactile printer) advanced CCTV, scanners and optical character recognition software (technology that scans printed text and provide the user with speech output), computer screen readers, Compact Discs (CDs) and multiple hardware and software innovations (Gerber, 2003; Ndung'u, 2011).

Digital formats not only offer increased accessibility, but also can enhance motivation for those students who are visually impaired who struggle with reading or who have difficulty coping with the unwieldiness of traditional formats. DAISY originally emerged as a new 
technology designed to meet the need for accessible audio for individuals unable to read print as easily and efficiently as a sighted person uses a printed book. It is an extensible markup language- based open standard (Spooner, 2014).

DAISY is useful and advised to all the users categories: teachers, students, parents -the audio support stimulates and increases the level of reading. The students felt encouraged, supported, motivated and finally, they required more DAISY books. The opinions are different according to the attitudes, the technical experience, the practice difficulties, but generally speaking, they are positive (Nes, 2007; Padure, 2008).

However,some studies
concluded that the lack of
information held by students, teachers and parents concerning the use of DAISY may lead to their belief that it is not suitable to the teaching/learning style. A lot of the students are avoiding its use in the classroom because of the fear of being "different". That is why, they use DAISY at home or in school, but not in the teaching time. These studies emphasized the need of a greater knowledge for the teaching staff concerning DAISY format, including data about the technical aspects in this field (Lundgren, 2002; Bredtvet Resource Centre, 2004cited in Nes, 2007; Lundeland, 2006).

It could be concluded that visually impaired pupils encounter difficulties in reading comprehension. The reason is not that they have weaker intellectual abilities than their sighted peers. The reasons can be attributed to various sources. On one hand, their visual impairment deprives them from making use of visual elements in the reading material, and using Braille makes their reading speed slower than their sighted peers. On the other hand, their working memory makes it hard for them to remember details of the reading text, resulting in an increased cognitive load while reading. Finally, lack of assistive technological resources could be a third source of these difficulties. Consequently, a need for attempting to enhance reading comprehension skills of the visually impaired pupils and reducing their cognitive load while reading emerged. The current study attempted to do so through the use of a virtual environment based on DAISY technology.

\section{Context of the problem:}

The VI pupils study the same curriculum presented to their sighted peers with only some adaptations like deleting pictures, some guessing exercises and drillings. The deleted parts are substituted with lists of words out of their natural context, and pupils are asked to memorize these lists as they are, which ultimately leads to verbalism. In addition, the teacher's guide is directed only to teachers of the sighted; no advice is given to teachers of the VI on the methodology and teaching aids appropriate to this category of pupils in order to facilitate learning English and practicing its 
skills. Finally, most teachers use lecturing techniques almost all the time. They barely engage pupils in learning strategies that address their potential capabilities or intelligences. They think that vision loss prescribes dictating pupils answers for expected questions in exams to memorize them only (Mohamed, 2004; Shoeir, 2009; Quatraro, 2011; Başaran, 2012; Abdelhady, 2014).

In spite of the importance of developing EFL reading comprehension skills, it can be declared that teaching reading comprehension at Al Nour schools for the VI has been restricted to loud reading of texts, dictating the answers of comprehension questions and getting pupils to rehearse them for exam. Being restricted to Braille reading, visually- impaired pupils suffer from difficulties in reading related to speed, proficiency and consequently comprehension. Thus, VI pupils lack essential EFL reading comprehension skills; a window that should be wide open for them to acquire knowledge and explore cultures.

In addition, this problem was further substantiated by informal interviews conducted by the researcher with the English language teachers at Al Nour schools for the VI in Mansoura City. During these interviews, teachers were asked certain questions, such as: "How do you teach EFL reading comprehension skills? What are some activities that you use to develop reading comprehension?
Have you ever tried to implement modern technological applications in your classes?". Results of these informal interviews showed that teachers suffer from very limited choices in their teaching; as their focus is mainly on teaching for passing the exams, and thus they exert tremendous efforts in dictating questions and their answers for the pupils to memorize. Consequently, chances of varied meaningful practice of reading comprehension skills are rare. Furthermore, modern technological applications are rarely attempted in the classroom because of very limited resources.

In addition to the informal interviews undertaken by the researcher with the EFL teachers at AlNour school for the VI pupils, the current research problem is determined after a set of clues has been inferred that can be explained as follows:

1. The visually impaired are not generally different from their sighted peers regarding their learning ability, as they can carry out all activities and tasks performed by sighted students using modified tools and materials suitable for the nature of their visual impairment (Basaran, 2012).

2. Thinking about how to overcome the difficulties imposed by the visual impairment should be the basis of the educational philosophy of the visually impaired (Shoeir, 2009).

3. The scarcity of studies and researches that investigated the problems of the visually impaired 
in EFL field in general, and those dealt with employing advanced technological applications in developing reading comprehension skills and reducing the cognitive overload of pupils with visual impairment at the preparatory stage.

\section{Statement of the problem:}

The problem of the study can be identified in the poor performance of VI pupils at the preparatory stage in EFL reading comprehension skills and the remarkably high cognitive load of reading; leading to poor performance in reading activities and in English lessons in general. Hence, the current study sought to find an answer to the following main question:

What is the effectiveness of designing a virtual environment based on DAISY technology in improving EFL reading comprehension skills of visuallyimpaired pupils at preparatory stage and reducing their cognitive load while reading?

The following sub-questions were sought to be answered:

1. What are the design standards of the virtual environment based on DAISY technology for developing EFL reading comprehension skills of preparatory stage VI pupils and reducing their cognitive overload?

2. What is the instructional design of a virtual environment based on DAISY technology for developing EFL reading comprehension skills of preparatory stage VI pupils and reducing their cognitive overload?

3. To what extent is the proposed virtual environment based on DAISY technology effective in developing EFL reading comprehension skills of the VI pupils at the preparatory stage?

4. To what extent is the proposed virtual environment based on DAISY technology effective in reducing the cognitive load while reading of the VI pupils at the preparatory stage?

\section{Hypotheses of the study:}

The current study attempted to verify the following hypotheses:

1. There is a statistically significant difference at (0.05) level between the mean ranks of the experimental and control group pupils' scores on the postadministration of the reading comprehension skills test in favor of the experimental group.

2. There is a statistically significant difference at (0.05) level between the mean ranks of the experimental group pupils' scores on the pre- and postadministrations of the reading comprehension skills test in favor of the post- administration.

3. There is a statistically significant difference at (0.05) level between the mean ranks of the experimental and control group pupils' scores on the post- 
administration of the cognitive load scale in favor of the experimental group.

4. There is a statistically significant difference at (0.05) level between the mean ranks of the experimental group pupils' scores on the pre- and post- administrations of the cognitive load scale in favor of the post- administration.

Instruments of the study:

The following instruments were designed and used in the present study:

1. Design and production standards Checklist: for determining the design standards for the DAISYBased virtual environment for developing reading comprehension skills of the visually- impaired pupils at the preparatory stage and reducing their cognitive load while reading.

2. A reading comprehension test: to be used as a pre- and posttest for assessing the pupils' reading comprehension skills before and after implementing the proposed virtual environment based on DAISY technology. (Prepared by the researcher)

3. A cognitive load Scale: to assess pupils' cognitive load while reading before and after implementing the proposed treatment. (Prepared by the researcher)
Purpose of the study:

The present study aimed at:

1. Proposing a framework for designing virtual environments based on DAISY technology for visually- impaired pupils that considers the nature of their disability.

2. Determining the effectiveness of using a virtual environment based on DAISY technology in developing second year preparatory stage VI pupils' reading comprehension skills.

3. Determining the effectiveness of using a virtual environment based on DAISY technology in decreasing second year preparatory stage VI pupils' cognitive load while reading.

\section{Significance of the study:}

It is hoped that the current study would contribute to:

1. Keeping teaching to the visuallyimpaired up-to-date with recent trends in the field of educational technology.

2. Developing the EFL reading comprehension skills for the visually- impaired pupils at the preparatory stage, and reduce their unnecessary cognitive load while reading.

3. Proposing a virtual learning environment based on DAISY technology that can be used for developing EFL language skills.

4. Directing the attention of teachers to exploit the potentials of the virtual environments in education, and asserting their 
role in overcoming many problems, especially in the education of the visuallyimpaired as an approach for adapting teaching to their needs.

5. Directing the attention of specialists and curriculum developers to employ modern educational technologies in education for visuallyimpaired learners that may help in reducing their cognitive load.

6. Raising the awareness of special education curriculum designers towards the necessity of adapting VI EFL textbooks to suite the visual impairment and exploit their remain senses.

7. Attracting the attention of researchers in the field of EFL for special education in general and for VI pupils in particular; as this field is currently, although very important, still under- researched.

Delimitations of the study:

The current study was restricted to the following delimitations:

1. The content: Module three in New Hello! English for preparatory schools, Year two, first term. It includes three units: Unit 7 "What's on TV?", Unit 8 "In the news", and Unit 9 "Communications".

2. Participants: A sample of second year preparatory stage visually- impaired pupils at AlNoor School for the VI in Mansoura City, West Mansoura
Educational Directorate assigned as an experimental group. In addition, a control group of VI pupils at the second year preparatory stage were selected from Damietta School for the VI.

\section{Definition of terms:}

\section{DAISY Technology:}

DAISY is an acronym for "Digital Accessible Information SYstem". DAISY is a framework to produce, store, record and play and read digital books. DAISY book includes text file (xml, html), image file and sound file (Mp3 or wav) (DAISY Consortium, 2007).

\section{Visually- Impaired pupils:}

Visually- impaired pupils are "learners who have visual acuity of $6 / 60(20 / 200)$ or less in the better eye with correction. They have either no vision, or, at most, light perception". Such pupils receive the educational services at Al-Nour schools all over the Egyptian governorates. They learn through the use of Braille and other media that utilize the remaining senses.

According to Davis (2003), the term 'visual impairment' refers to "children who are classed as blind or as having low vision. The nature and degree of visual impairment may vary significantly, so each student may require individual adaptations to instructional practices and materials in order to learn effectively". On the other hand, Visual impairment refers to "the function of the eye and can be measured with tests such as visual acuity, visual field, color vision, and contrast sensitivity". 
Division of visual impairments according to National Dissemination Centre for Children with Disabilities: ${ }^{1}$

Partially sighted - the term refers to "a person with some type of visual difficulty which results in the need of special education".

Low vision - there is a severe visual impairment in a person. It does not necessarily have to be a distance vision problem. The term applies to all individuals who are unable to read a newspaper text common size at normal reading distance and this disability cannot be corrected by glasses or lenses. These people usually use another sense or possibly other senses to learn. Some of them may make use of additional lighting and / or text size change.

Legally blind - a person has less than $20 / 200$ sight in the better eye (the first number indicates the length in meters needed by a visually impaired person to see an object and the second number indicates the length in metres needed by a nonvisually impaired person to see the same object). This is often accompanied by a very limited vision field.

Totally blind - those people have to learn with the help of Braille print and other non-visual aids. Some of the people are able to recognise darkness and light, some of them do not perceive the difference at all.

\footnotetext{
${ }^{1}<$ http://nichcy.org/disability/specific/ visualimpairment $>$ [23.2.2012]
}

\section{Reading Comprehension:}

Reading comprehension is defined as an "active process of comprehending where students need to be taught strategies to read more efficiently (e.g, guess from the context, define expectations, make inferences about the text, skim ahead to fill in the context, etc." (Grabe,1991).

James (2000) added that reading comprehension could be defined as an active process that the reader can use his background knowledge in order to construct meanings while he is reading a text.

Reading comprehension is operationally defined in the current study as the process in which the visually- impaired pupils pass the level of merely identifying letters and words to the ability of interacting with the text in a meaningful way to practice and master the identified subskills with the aid of the proposed DAISY- based virtual environment.

\section{Cognitive Load:}

Cognitive load theory (CLT) can be defined as a theory of learning and instructional design principles based on assumptions about human cognitive architecture (Sweller, 2004; Van Merriënboer \& Ayres, 2005).

Cognitive load (CL) is defined as the "total amount of mental energy imposed on working memory at an instance in time" (Cooper, 1998, p. 10).This "total" cognitive load is further subdivided into three subcomponents: intrinsic cognitive load (ICL), extraneous cognitive load (ECL) and germane cognitive load (GCL) (Sweller et al., 1998). 
Cognitive load is defined as "a multidimensional construct representing the load that performing a particular task imposes on the learner's cognitive system" (Paas et al., 2003).

In the current study, cognitive load is operationally defined as: the total amount of mental energy exerted by visually-impaired pupils while performing an EFL reading comprehension task. It is measured through the "cognitive load in reading scale" and it is assumed to be low among experimental group pupils after experimentation.

\section{Review of literature:}

The following section sheds more light on the main variables of the current study which are visuallyimpaired pupils, reading comprehension skills of the visuallyimpaired, cognitive load theory and the DAISY technology.

Reading Comprehension Skills of Visually- Impaired Learners :

Reading is an important task to all individuals in order to function in today's society as it is an essential way to develop minds. Likewise, reading considers as an indispensable part to learn new concepts, knowledge, and even to build someone's character and its maturity as well. In the context of learning, reading is an integral element of learning process. In addition, it has been clearly seen that learning has been shifted from learning to read into reading to learn (Ghanimi et al., 2016).
In many second or foreign language teaching situations, reading receives a special focus. There are a number of reasons for this. First, many foreign language students often have reading as one of their most important goals; they want to be able to read for information and pleasure, for their career, and for academic purposes. Second, written texts serve various pedagogical purposes. Extensive exposure to linguistically comprehensible written texts can enhance the process of language acquisition. In addition, good reading texts provide good models for writing, and provide opportunities to introduce new topics, to stimulate discussion, and to study language (e.g., vocabulary, grammar, and idioms). Reading then is a skill which is highly valued by students and teachers alike (Richards\& Renandya, 2002).

Nunan (1999) considered reading as a process of obtaining information and making sense of the text. He differentiated between two views of reading; the first is reading as a process of decoding written symbols and the second is reading as a process of reconstructing meaning. In the same context, Paris \& Stahl (2005) stated that reading involves two sub-skills; decoding and comprehension. Decoding is a simple skill which can be taught and assessed in direct ways. Comprehension on the other hand is a complex skill which depends mainly on a number of factors, contexts and certain reading goals. Reading comprehension is the core of the reading activity, it enables students to 
make sense of what the texts tell about and to understand the written language.

Sadler (2001) stated that reading comprehension is a complex process which is described as involving identification of letters, recognition of words, visual discrimination and thus sampling of ideas, predicting the decoding and the intended meaning of the message. Reading comprehension is also defined by Partnership for Reading (2005) as understanding a text, or the process of extracting meaning from a text. Comprehension is a "construction process" because it involves all the elements of the reading process working together to make a representation to the text in the reader's mind. In addition, reading comprehension has been defined as a process of constructing and extracting meaning from written texts, based on a complex coordination of a number of interrelated sources of information (Mastropieri \& Scruggs, 1997).

Concerning visually impaired foreign language learners, it is assumed that they experience more difficulties in their foreign language learning than sighted learners as they need adaptive and technical accommodations in their learning process. In addition, their opportunities for implicit foreign language learning are more limited. There are several obstacles connected with the absence of visual information and a necessity for adapted study and testing materials (Lõvi, 2013).
Studies on comprehension of low vision children showed different results. One study compared reading performance of low vision students with their age- matched sighted peers using the Neale Analysis of Reading Ability (Douglas et al., 2002). They found that low vision students lag behind in all aspects of reading, namely accuracy, speed, and comprehension. Other studies, however, found that visually- impaired children need more time and effort to read and comprehend a text; but they seem to use this time with enough efficiency to process semantic and syntactic information (Gompel et al., 2004, Mohammed\& Omar, 2011). Thus, children with low vision are as good as sighted children in comprehending texts (Gompel et al., 2002).

Of all sensations perceived through our senses, those received through sight have by far the greatest influence on perception. Sight combined with the other senses, mainly hearing, allow us to have a world global perception and to perform actions upon it. After sight, hearing and touch are definitively the second and third major human senses, respectively. For the blind, they evidently become the first and second ones, respectively (Velázquez, 2010).

As students progress through the grades into the upper elementary and middle school years, the demand of reading increases enormously. Supplementation with speech is, therefore, considered a necessary tool for increasing access to information not only to compensate for depressed 
reading rates but also because braille and large print materials have not always been available when needed. Today, however, advances in the production of digital media and in the design of technology tools have reached a point where they allow braille or print readers to process tactile or visual information at the same time they are engaging with text in an auditory format. Newer technologies offer features that allow a user to more efficiently access and manipulate the braille, print, and audio information conveyed (Jackson\& Presley, 2012).

ASR (Audio-supported reading) is an approach for improving the reading proficiency of students who are blind or visually impaired. Improvement of reading proficiency should translate into greater academic achievement as students enjoy increased opportunity to learn by reading after they have learned to read (Jackson\& Presley, 2012). The reader will be actively engaged in the process of audiosupported reading and in controlling the distribution of cognitive load depending on the demands of the task and the ultimate purpose for reading. ASR's ability to allow a reader to control the rate at which text is presented and to decide which modality will take precedence during reading tasks allows for sustained engagement and freedom from distraction. Working with a DAISY format file, for example, students can access the information contained in the file from a wide variety of devices, players, PCs, tablets, or smartphones (Esteves, 2007; Lesnick, 2006).

Based on the fact that the visually- impaired perceive the world and classroom activities in a quite different way from those without any impairment, techniques that are used to educate the visually impaired in general and teaching them English as a foreign language in particular and theoretical assumptions underlying such teaching or instruction are supposed to be rather different (Başaran, 2012). However, Hallahan and Kauffman (1991) agreed that visually impaired students should be educated in the same general way as sighted children. The main difference is that visually impaired students will have to rely on other sensory modalities to acquire information. All in all, studies conducted in FL education of VI yielded common results which revealed that VI students can learn a foreign language like their sighted peers, if they are provided with adequate teaching methods and strategies. Vision loss is not a barrier for the FL education of the VI, yet environmental challenges affect their learning process (Hassan, 2017).

Most studies conducted in the field of reading performance and comprehension of the visuallyimpaired readers focused on assessing their performance when compared to their sighted peers. Most of these studies revealed that VI students have delays in speed, accuracy and fluency in reading, however, there were insignificant differences in comprehension (Douglas et al., 2002; Hill et al., 2005; Gompel et al., 2004). 
Few studies had been attempted for developing reading comprehension skills for the visually- impaired students. Cooperative Integrated reading and composition (Circ) method which emphasizes group learning activities, for example, proved to be effective in improving reading comprehension of 3 rd grade VI pupils (Gunarhadi\& Sunardi, 2017). In addition, a more recent study by McLaughlin and KameiHannan (2018) indicated that using an $\mathrm{iPad}$ as a medium for reading may have an effect on reading fluency and comprehension for students with low vision.

\section{Cognitive Load (CL):}

Cognitive Load Theory takes into account the limitation of working memory, considering that few elements of information can be processed in working memory at the same time, and too many elements may overburden it and reduce the effectiveness of processing (Van Merrienboer \& Sweller, 2005). From a cognitive load perspective, this working memory capacity and limitations only apply to novel information attained where no schema-based executive knowledge is available (Shehab, 2011). Therefore, in learning process, to improve the academic performance and learning quality, the limited working memory should be fully used and the unrelated cognitive load should be decreased as much as possible (Zhang, 2013). In addition, CL theory suggests that effective instructional material facilitates learning by directing cognitive resources toward activities that are relevant to learning rather than toward introductions to learning (Chandler \& Sweller, 1991).

Cognitive overload occurs when "the total cognitive load exceeds the working memory capacity of the learner" (Gerjets, Scheiter \& Cierniak 2009 , p. 45). If the working memory is overloaded, there is "a greater risk that the content being taught will not be understood by the learner, will be misinterpreted or confused, will not be effectively encoded in long-term memory, and that learning will be slowed down" (Martin 2016, p. 8).

Types of Cognitive Load:

CLT distinguishes between three types of cognitive load: extraneous, intrinsic, and germane cognitive load. Some forms of cognitive load are useful, while others waste cognitive and mental resources. Since the total mental capacity is limited, learners need to balance the three forms of cognitive load to maximize learning efficiency. In particular, an effective instruction should consider minimizing the unproductive intrinsic and extraneous cognitive load while stimulating the desirable germane cognitive load (Sweller et al.,1998; Shehab, 2011).

\section{1- Intrinsic cognitive load:}

This type of cognitive load refers to the amount of cognitive processing required to comprehend material and depends on the number of information elements simultaneously processed in working memory to understand what has been learnt, their interactivity; i.e. complexity, along with the use of learners' expertise 
(Sweller et al., 1998; Sweller, 2010). However, many theorists agree that intrinsic cognitive load can be altered by instructional techniques that make complex material easier to learn. It is claimed that intrinsic cognitive load can be manipulated through sequencing the material either in a simple-to-complex order so that learners do not experience its full complexity at the outset is a way to control intrinsic load (Van Merrienboer et al. 2003), or in isolated-to-integrated elements (Pollock et al., 2002; Ayres; 2006), or in part-whole sequencing (Gerjets et al., 2004).

\section{2- Extraneous cognitive \\ load:}

This cognitive load is regarded as 'ineffective cognitive load'. In other words, Sweller (1994) explains that it is caused by ineffective instructional techniques which do not engage learners in schema construction and automation. In addition, ineffective instructional techniques simply add more loads in working memory, resulting in less capacity in working memory to process new information (Sweller et. al., 1998). Therefore, all information processing irrelevant to the goals of instruction represents extraneous load (Mayer, 2008). Four general sources of extraneous cognitive load are cited in the literature (Jong, 2010) . First, the "split-attention" effect refers to the separate presentation of elements that require simultaneous processing. In this case, learners must keep one domain element in memory while searching for another element in order to relate it to the first. Split attention may refer to spatially separated elements or temporal separation of two elements, as in multi-media presentations (Ayres and Sweller, 2005). This can be remedied by presenting material in an integrated way (e.g., Cerpa et al. 1996; Chandler and Sweller 1992; Sweller and Chandler, 1991).

A second identified source of extraneous cognitive load is when students must solve problems for which they have no schema-based knowledge; i.e. conventional practice problems (Sweller 1993). In this situation students may use meansends-analysis as a solution procedure (Paas and van Merrienboer 1994). Though this is an effective way of solving problems, it also requires keeping many elements (start goal, end goal, intermediate goals, operators) in working memory. To remedy this, students can be offered "goal free problems", "worked out problems" or "completion problems" instead of traditional problems (Atkinson et al. 2000).

A third source of extraneous load may arise when the instructional design uses only one of the subsystems of working memory. More capacity can be used when both the visual and auditory parts of working memory are addressed. This "modality principle" implies that material is more efficiently presented as a combination of visual and auditory material (Sweller et al. 1998; Tindall-Ford et al. 1997).

A fourth source of unnecessary load occurs when learners must 
coordinate materials having the same information. Cognitive resources can be freed by including just one of the two (or more) sources of information. This is called the "redundancy principle" (Sweller 2005; Sweller et al. 1998).

Consequently, instructional design is considered most effective when it minimizes extraneous load in order to free up the capacity of working memory. Theorists of cognitive load have identified a number of instructional approaches that work to reduce extraneous cognitive load in order to increase the efficacy of instruction (van Merrienboer and Sweller 2005). Split-attention effects, for example, are reduced if information is given in condensed rather than separated mode (e.g. comments integrated into a figure).

\section{3- Germane cognitive load:}

Artino (2008) describes this type of cognitive load as 'effective cognitive load' which helps promote learning. It refers to the load imposed on the working memory by the process of learning- that is, the process of transferring information into the long-term memory through schema construction (Sweller, van Merrienboer \& Paas, 1998). For this reason, germane cognitive load can be understood in simple terms as the 'good' type of cognitive load. Furthermore, it refers to any load which is related to processes required in schema construction and automation (Pass et. al., 2003). The construction of schemas involves deep cognitive processes such as interpreting, exemplifying, classifying, inferring, differentiating, and organizing (Mayer, 2008).

It can be concluded that germane CL is mental processing that is imposed by instructional design that positively contributes to attaining better learning outcomes. It contributes to construction of cognitive structures and productive cognitive processes that enhance performance (Renkl, Hilbert \& Schworm, 2009; Van Merrienboer, Kester, \& Paas, 2006). It can also be a factor that promotes depth of processing, enhancing a learner's ability to organize and integrate learned material (Stull \& Mayer, 2007), which helps in achieving instructional goals. Instructional designs should consequently try to stimulate and guide students to engage in schema construction and automation and in this way increase germane cognitive load.

Theorists of cognitive load assert that instructional material has maximum effectiveness when it reduces extraneous load (which is not relevant to learning) and increases germane load (which is directly relevant to learning). Gerjets, Scheiter and Cierniak (2009) explain that germane load is 'caused by a supportive instructional design and is helpful for effective learning' (p. 45). For this purpose, tasks of high variability and an appropriate level of guidance are advantageous (van Merrienboer et al., 2006). Finally, concerning the measurement of cognitive load, Paas et al. (2003) concluded that rating scales are the most popular tools to measure mental 
effort and cognitive load, because they are easy to use; do not interfere with primary task performance; are inexpensive; can detect small variations in workload (i.e., sensitivity); are reliable; and provide decent convergent, construct, and discriminate validity(p. 68).

\section{Theory and Foreign Language Instruction:}

The effect of CL theory and its entailed principles was clear in many studies that dealt with foreign language teaching (Kanokpermpoon, 2014). Teaching vocabulary, for example, was proved to be done best when students are exposed to both reading and listening, i.e. modality effect (Sydorenko, 2010; Lin\& Yu, 2012). Moreover, in grammar instruction, it is suggested to integrate materials into a single design, thereby there will be less split-attention in students' working memory. Consequently, students can gain more comprehension and retention in learning grammar (Sakul-Thanasakdi, 2001- cited in Kanokpermpoon, 2014; Giumelli, 2012). In writing instruction, when students are exposed to worked example with holistic approach, i.e. whole-part sequencing with simple backward chaining, learning can be transferred, thus increasing germane cognitive load and promoting schema construction (Si\& Kim, 2001). Furthermore, it is concluded that listening and speaking are performed best when a learner works in a low working condition, i.e. less splitattention effect. In addition, the redundancy effect of listening and reading can be minimized when a foreign language student exposes to the reading text prior listening (Farris et al., 2008; Moussa-Inaty, Ayres \& Sweller, 2011).

As for teaching reading comprehension, split-attention and redundancy effects can be reduced, allowing more capacity in working memory to process when the teacher adjusts his/ her teaching by not providing too much information related to the text, and when the comprehension questions are integrated into the text ( $\mathrm{Yu}, 2002$; Hung, 2009). Al-Shehri and Gitsaki (2010) in another study showed that students who were in integrated groups performed better than students in split attention groups on reading comprehension tasks. Furthermore, students who used an online dictionary scored higher on the vocabulary test than students who did not. However, the results of a study conducted by contradict the findings of Al-Shehri \& Gitsaki, (2010) and Hung (2009). It supports the use of online materials with a split attention format in reading tasks. Therefore, based on the students' needs, abilities and interests, teachers can integrate computer technologies into their English language instruction without concern about cognitive overload. This can be done by either selecting appropriate materials from the vast resources of the Internet or converting printed materials to hypertext, as was done in this study.

Cumulatively, prior studies have provided powerful evidence indicating that material should typically be presented without redundant features, 
and that materials that cannot be understood in isolation should be physically integrated. Second, selfexplanatory, integrated diagrams are presumed superior when redundant and incidental materials are removed. Third, split attention and redundancy effects are equally applicable to multimedia instructional modalities that incorporate dual channel strategies. Fourth, learning and transfer are both favored by strategies that eliminate split attention and redundancy in technical areas and last, conditional factors such as learner experience must be accounted for within a given knowledge domain (Pollock, Chandler,\&Sweller,2002; Meissner\& Bogner, 2013; Taylor, 2013).

These ideas of reducing cognitive overload resulted in the emergence of load reduction instruction (LRI) which is an umbrella term referring to instructional approaches that seek to reduce and/or manage cognitive load in order to optimize students' learning and achievement. LRI is an approach to teaching that reduces the cognitive load on students in order to optimize their learning and achievement. LRI initially involves explicit instruction, then, at the appropriate point in learning, it also involves less structured approaches such as guided discovery-, problem-, and inquirybased learning (Martin, 2016). Therefore, there is a clear necessity to deliver instruction and develop instructional material that optimally assists the processing of information to long-term memory from working memory and that frees working memory from unnecessary burden or load (Martin 2016; Martin \& Evans 2018). This is the primary aim of LRI and its principles as illustrated in the following figure:

Figure1:Load Reduction Instruction Framework(Source: Martin,2016)

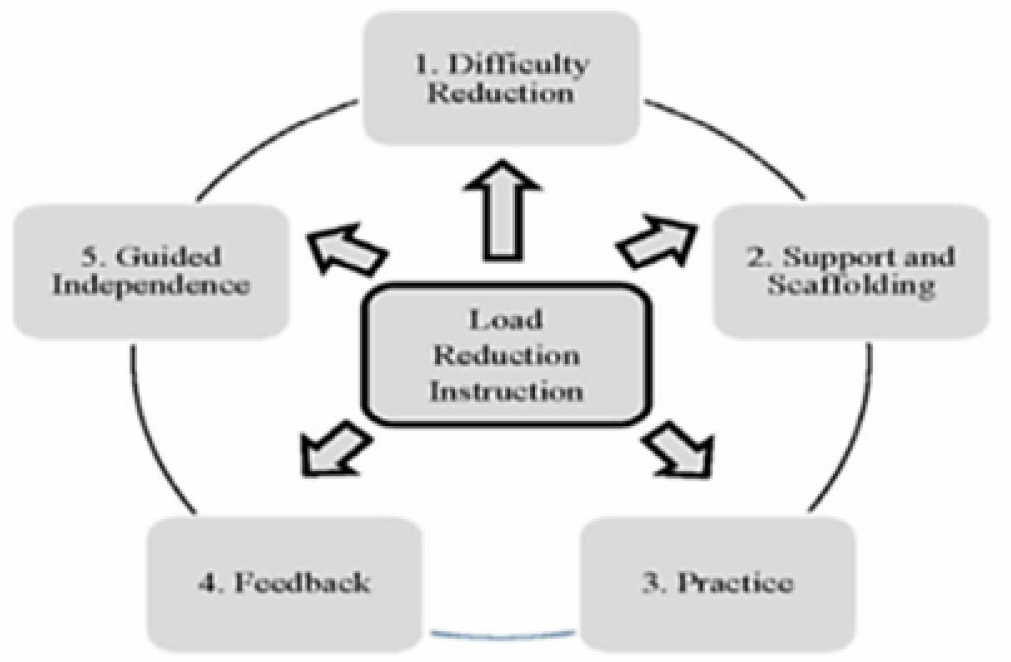


Cognitive load is one of important factors that influence elearning outcomes. Therefore, in the web-based foreign language learning, the cognitive load of learners must be considered carefully. To obtain a successful learning process, learners' extraneous and intrinsic cognitive load should be greatly decreased and germane cognitive load can be properly increased (Zhang, 2013).

\section{Digital Audio Based Information System (DAISY):}

Information Technology (IT) is a broad subject which deals with the use of electronic computers and relevant software to convert, store, protect, process, transmit and retrieve information (Rendulic, 2011). Over the past twenty years, its prevalence has dramatically increased such that it is now a part of nearly every aspect of daily life. Information technology as a social system is recognized worldwide as a tool that accelerates economic and social integration (Nkiko et al., 2018).

Information Technology has revolutionized and expanded both accessibility and availability of various formats into which reading materials for the visually impaired could be transcribed. Evans (2000) described access to technologies such as the Kurzweil Reading Machine and Closed Circuit Television (CCTV) as having greatly assisted in the provision of information to the visually impaired in recent times. The most radical innovation came with the widespread use of computers where visually impaired people could easily convert print into electronic text and read it from the screen with either transitory Braille or through synthetic speech. It is also possible to link different converters such as scanners, reading machines, embossers and tape recorders, so that a converter text can be permanently recorded in the desired format (Long, 1993; Gallimore, 1999).

DAISY is a framework to produce, store, record and play and read digital books. DAISY book includes text file (xml, html), image file and sound file (Mp3 or wav) (DAISY Consortium, 2007). DAISY books can be read through CDs, DVDs or internet applications on computers or smart phones. In addition to the files included in DAISY, it contains synchronization files which allow the free navigation through the book bringing a similar experience to the print books. Readers are able to navigate the whole book, move to the desired part, specific page or even word. Reader can also skip to the index and go back to the text, use bookmark, create comments, use dictionary and even listen to specific word, look up a word in a dictionary and also search for a text. Users have the opportunity to access DAISY from several devices; DAIASY players, computers, smart phones, tablets, IPad, etc. (Spooner, 2014).

DAISY is an international standard developed by a consortium of users and is therefore designed for the users. It has various advantages as follows:

1. DAISY books are multi- sensory and are therefore an ideal 
learning media for print impaired and visually- impaired students who are restricted by text only materials

2. Software DAISY players enable dyslexic students make the association between the spoken word and the corresponding text, improving their rate of learning.

3. DAISY audio can be quickly and easily created from Word documents using commercial production tools - so no need for time consuming narration.

4. It is an optimal format for education environments because of its suitability for a variety of needs such as visually- impaired students, dyslexic students and anyone with additional literacy needs.

5. Its files are digital and fully navigable, so users can scan forward, backward and bookmark important words and paragraphs - similar to hard copy book readers.

6. Software DAISY players enable students to customize the appearance of text and create bookmarks and notes against files, just like colleagues using print might make notes in the margin.

7. Because DAISY files are digital and small they can easily be archived and reused for different purposes unlike some other alternative formats.
8. Up to 40 hours of navigable speech and audio will fit onto one $\mathrm{CD}$ or be distributed over the internet.

Tank and Frederiksen (2007) added that when talking books were originally developed, readers were interviewed about their comments. Readers' comments were about that analogue recordings did not meet their expectations and did not motivate them to read. Poor access to certain points and poor sound system quality annoyed them which help in the new innovation of DAISY books to solve these problems.

Several researchers investigated the effect of DAISY technology on various learning aspects. For example, Bredtvet Resource Centre (2004) conducted a study to test using DAISY books of students with reading and writing difficulties. Seven students of $6^{\text {th }}$ to $10^{\text {th }}$ grades participated for over five months. Results showed that DAISY is a useful and advantageous tool in developing reading and writing.

Other studies focused on using DAISY with special needs learners. Lundeland (2006) interviewed six students of secondary schools and their teachers. Results revealed the importance of using DAISY as an educational tool to overcome learning difficulties of learners with special needs. Furthermore, Nes and Ribu (2007) investigated how DAISY is used in reading instruction with students who suffer from reading $\mathrm{di} \square$ culties or dyslexia. Data were collected through questionnaires and surveys for students and teachers. The 
results of the study show that students approved that using DAISY helped them to learn, easy to use and efficient.

In addition, Lundh and Johnson (2014) studied using DAISY books with print disabilities readers. Twelve empirical studies were conducted. The research focused on using talking books and social settings where talking books are used. Findings of the study revealed that navigational features of DAISY provide new approaches to reading. Also the results depended on the why and how DAISY is used.

Finally, Spooner (2014) designed a qualitative pilot study to determine advantages and disadvantages of DAISY books compared with traditional reading. Twelve students at the secondary stage participated in the study. The study included training, interviews and focus group. It was concluded that DAISY had positive response and advantages over traditional approaches of reading.

The modern web technology provides enabling environment for students to explore knowledge as well as the communication convenience for them to interact. Virtual learning environments are hugely diverse in size, capability and services offered can cater for individuals ranging in attainment, ages and special needs. Virtual classrooms are of three broad categories - independent, collaborate and broadcast (Atasi et al, 2008; Adewale, Ibam\& Alese, 2012).
To sum up, it can be concluded that modern educational technologies provide a wide range of tools that have the advantage of enhancing the teaching/ learning process and optimizing students' achievement, interest and engagement in learning. Moreover, DAISY technology represents an overwhelming source of practical tools and applications that facilitate learning specially for the visually impaired. With special reference to virtual learning environments, they provide students with multiple chances for interaction, searching for information, and developing many language skills. Therefore, integrating DAISY applications within a virtual environment maximizes the opportunity of students' achievement and development.

\section{Methodology:}

\section{Sampling:}

Purposive sampling is used when the researcher targets a group of people believed to be typical or average, or a group of persons specially picked for some unique purposes. Since the study targeted visually impaired pupils at the preparatory stage, purposive sampling method was adopted to select participants of the current study.

\section{Participants:}

Participants of the study were second year preparatory stage pupils. Two intact classes were assigned as a control and experimental groups. the control group included a class of five pupils at Damietta school. The experimental group comprised of a 
class of five pupils at Al-Nour school for the visually-impaired in Mansoura. Pupils' age ranged between fourteen and fifteen years old. Most of the participants in both groups were visually-impaired since birth, while few of them suffer from severe low vision. They had the same experience of learning English as a foreign language at the same schools; both for Damietta and Mansoura groups.

Design of the study:

The current study adopted the quasi-experimental design using a pretest- posttest two independent groups; one is experimental and the other is control, to investigate the effectiveness of DAISY Technology- based virtual environment in developing the reading comprehension skills and reducing the cognitive load of VI preparatory stage pupils. The following figure illustrates the experimental design of the current study:

Figure 2: The Experimental Design of the study

Pre-

administration

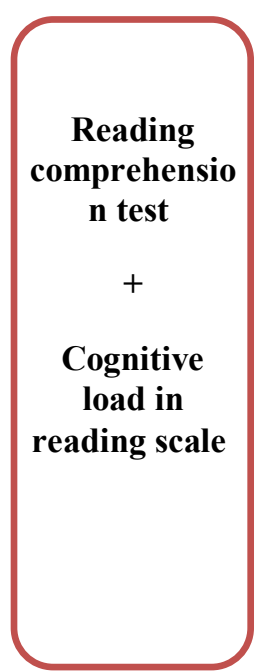

Post-

administration

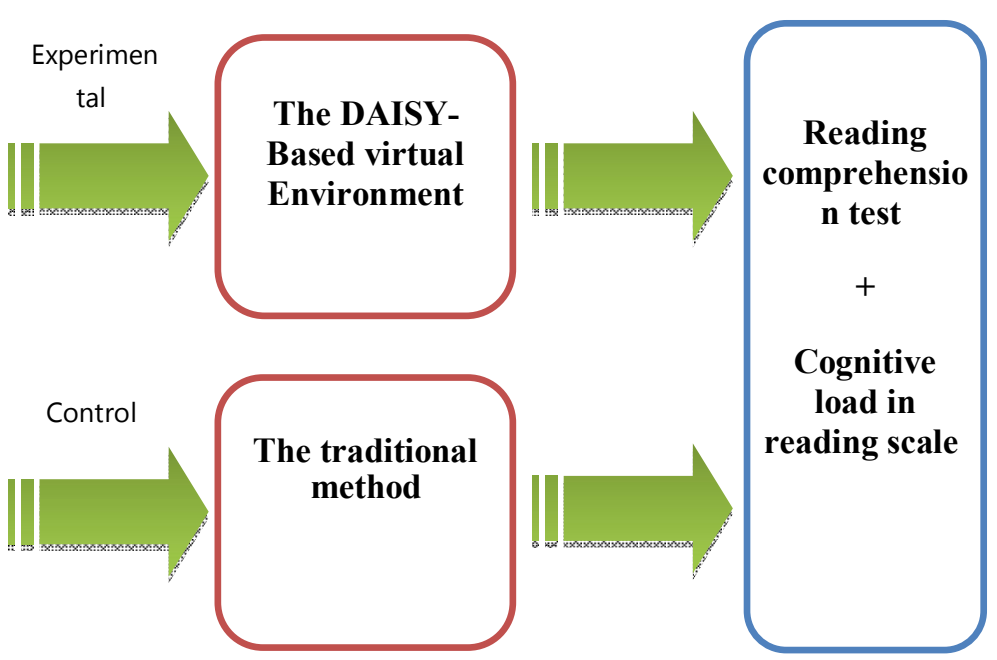




\section{Instruments:}

Three instruments were used in the current study: (available with the researcher upon request)

\section{(1) Design and production standards Checklist for the DAISY- Based virtual environment:}

The overall aim of designing that checklist was determining the design standards of the virtual learning environment that is based on DAISY technology for developing EFL reading comprehension skills of the visually- impaired pupils at the preparatory stage.

Here are the steps that the researchers had followed to prepare the list.

1. Constructing the checklist: The list of standards was built through analyzing previous literature and all studies related to instructional design standards. The list included in its initial form (18) criteria in the light of a three- point Likert scale of importance.

2. Validating the checklist: After preparing the list in its initial form, it was presented to educational technology specialists. The modifications were made and were approved by the jurors, and accordingly, the list of standards in its final form included (18) criteria, and (150) performance indicators.
(2) The Reading Comprehension Test:

The test was constructed in the light of the following resources:

- Reviewing previous studies concerned with speaking tests.

- The seven reading comprehension skills identified after reviewing "New Hello! English for second year preparatory stage, the first term.

The purpose of the test was to measure the actual level of the pupils' reading comprehension skills. After reviewing "New Hello! English for preparatory stage, the first term," the identified reading comprehension skills were included in the pre- post reading comprehension skills test. The test included five situational questions where the interlocutor asks a pupil to answer or asks two pupils to ask each other and provide answers. Each question covers a range of the specified sub-skills. It didn't include visual elements or pictures to suite the nature of visual impairment.

Test reliability:

Reliability of the test was calculated using Cronbach's Alpha method, which is based on calculating the variance in the items of the test, through which the extent of correlation between the test items to each other, and the correlation between each item with the total score of the test is illustrated. Results were as illustrated in the following table: 
Table1 :Cronbach's Alpha Reliability Coefficient for the Argumentative Writing Test

\begin{tabular}{|c|c|c|c|c|}
\hline \multicolumn{2}{|c|}{ Reliability co. } & No. of students & Question items & Value of Alfa co. $(\alpha)$ \\
\hline Alfa co. $(\alpha)$ & Total & 5 & 14 & 0.65 \\
\hline
\end{tabular}

Statistics in table (1) indicate that Cronbach's Alpha Reliability coefficient for the test was (0.65) which is an acceptable value. This implies that the reading comprehension test was reliable and suited the purposes of the study.

\section{Test validity:}

To measure test content validity, the first version of the test was given to EFL jury $(\mathrm{N}=4)$ to evaluate each question in terms of types of questions, difficulty level, arrangement and number of questions. The test proved to be valid as the jury approved all the questions. In addition, the calculated intrinsic validity for the speaking test was 0.81. Therefore, the test was considered valid for the purposes of the current study.

Table 2: Coefficients of Difficulty, Facility, and Distinction of the Reading Comprehension Test:

\begin{tabular}{|c|c|c|c|c|c|c|c|}
\hline $\begin{array}{c}\text { Questi } \\
\text { on no. }\end{array}$ & $\begin{array}{c}\text { Facility } \\
\text { indicator }\end{array}$ & $\begin{array}{c}\text { Difficulty } \\
\text { indicator }\end{array}$ & $\begin{array}{c}\text { Distinction } \\
\text { indicator }\end{array}$ & $\begin{array}{c}\text { Question } \\
\text { no. }\end{array}$ & $\begin{array}{c}\text { Facility } \\
\text { indicator }\end{array}$ & $\begin{array}{c}\text { Difficulty } \\
\text { indicator }\end{array}$ & $\begin{array}{c}\text { Distinction } \\
\text { indicator }\end{array}$ \\
\hline $\mathbf{1}$ & 0.72 & 0.28 & 0.45 & $\mathbf{8}$ & 0.48 & 0.52 & 0.50 \\
\hline $\mathbf{2}$ & 0.76 & 0.24 & 0.43 & $\mathbf{9}$ & 0.48 & 0.52 & 0.50 \\
\hline $\mathbf{3}$ & 0.28 & 0.72 & 0.45 & $\mathbf{1 0}$ & 0.20 & 0.80 & 0.40 \\
\hline $\mathbf{4}$ & 0.40 & 0.60 & 0.49 & $\mathbf{1 1}$ & 0.36 & 0.64 & 0.48 \\
\hline $\mathbf{5}$ & 0.48 & 0.52 & 0.50 & $\mathbf{1 2}$ & 0.36 & 0.64 & 0.48 \\
\hline $\mathbf{6}$ & 0.28 & 0.72 & 0.45 & $\mathbf{1 3}$ & 0.32 & 0.68 & 0.47 \\
\hline $\mathbf{7}$ & 0.40 & 0.60 & 0.49 & $\mathbf{1 4}$ & 0.28 & 0.72 & 0.45 \\
\hline
\end{tabular}

Statistics in the above table indicated that the facility and difficulty coefficients of the test items ranged between $(0.20$ and 0.80). This, in turn, indicated the suitability of the difficulty and facility of the reading comprehension test questions to the level of the targeted sample.
Estimating the coefficients of difficulty, facility, and distinction of the reading comprehension test:

The objective of estimating the difficulty and facility coefficients was to delete or modify the very simple question items, whose coefficient is more than $(0.8)$, and to delete or modify the very difficult question items whose facility coefficient is less than (0.2). Furthermore, the objective of estimating the distinction coefficient was to find out if each of the test items was able to distinguish the high and low levels of the target experimental sample. The test item would be considered non-distinctive if its distinction coefficient was less than (0.2) (El-Sayed, 1979). Results are illustrated in the following table: 


\section{(3) The Cognitive Load in Reading} Scale:

The cognitive load in reading scale aimed at assessing pupils' cognitive load level related to their performance in reading before and after implementing the proposed treatment. It consisted of twenty one statements; seven statements for each of the three types of cognitive load with a 5-point Likert scale type ranging from "Always" to "Never". Among the statements of the scale, eight negative statements were included for more valid responses from the pupils.

Concerning the process of scoring the responses on the scale and recording them, it was done in the light of the alternatives provided for the pupils; Never $=1$, rarely $=2$, sometimes $=3$, often $=4$, and always $=$ 5. The negative statements were scored in the opposite direction; Never $=5$, rarely $=4$, sometimes $=3$, often $=2$, always $=1$. The higher the score that the pupil would get, the greater cognitive load $\mathrm{s} / \mathrm{he}$ is supposed to have while reading. Consequently, it is hypothesized that the scores of the experimental group pupils on the post- administration of the cognitive load scale would be lower than the pre- administration of the same scale as a result of the proposed treatment.
Content validity of the scale:

In order to check the validity of the scale, it was presented to a group of jurors for validation and to suggest any recommended changes. Very few words were recommended to be changed and replaced with clearer ones. These suggestions were carried out and the difficult words were replaced with clearer synonyms that suite the level of the pupils. Furthermore, Jury members approved the statements of the third dimension of the scale; i.e. Germane cognitive load where the researchers favored negative statements for feasibility of statistical processing. According to literature review, Germane cognitive load was supposed to increase after implementing the proposed treatment, yet negative statements made the scoring of the three dimensions consistent. The scale was then ready for administration in its final form.

Reliability of the Cognitive Load in Reading Scale:

Reliability of the scale was calculated using Cronbach's Alpha method, which is based on calculating the variance in the items of the scale, through which the extent of correlation between the scale items to each other, and the correlation between each item with the total score of the scale is illustrated. Results were as illustrated in the following table:

Table 3: Cronbach's Alpha Reliability Coefficient for the CL in Reading Scale

\begin{tabular}{|c|c|c|c|c|}
\hline \multicolumn{2}{|c|}{ Reliability co. $(\boldsymbol{\alpha})$} & No. of students & Items & Value of Alfa co. $(\boldsymbol{\alpha})$ \\
\hline & Total & 5 & 21 & 0.70 \\
\hline
\end{tabular}

Statistics in table 3 indicate that Cronbach's Alpha Reliability coefficient for the scale was $(0.70)$

which is an acceptable value $\left(0.8^{*} \alpha \geq\right.$ 0.7). This implied that the Cognitive 
Load in Reading scale was reliable and suited the purposes of the study.

Homogeneity of the Control and Experimental groups:

For making sure that the two groups had the same level of reading comprehension skills and cognitive load in reading, both the Reading
Comprehension test and the $\mathrm{CL}$ in reading scale were pre- administered to both groups. A Mann-Whitney test was used for estimating the differences between the mean rank scores of the two groups on the two instruments. Results of the pre- administration are illustrated in the following tables:

Table 4: Results of Mann-Whitney test of the control and experimental groups on pre- Reading Comprehension Test

\begin{tabular}{|c|c|c|c|c|c|c|}
\hline Skills & Group & $\mathbf{N}$ & $\begin{array}{l}\text { Mean } \\
\text { Rank }\end{array}$ & Sum of Ranks & Mann-Whitney U & Sig. (2-tailed \\
\hline \multirow{3}{*}{ S1 } & Exp. & 5 & 6.00 & 30.00 & 10 & \multirow{3}{*}{ Not Sig. } \\
\hline & Cont. & 5 & 5.00 & 25.00 & & \\
\hline & Total & 10 & & & & \\
\hline \multirow{3}{*}{ S2 } & Exp. & 5 & 5.80 & 29.00 & 11 & \multirow{3}{*}{ Not Sig. } \\
\hline & Cont. & 5 & 5.20 & 26.00 & & \\
\hline & Total & 10 & & & & \\
\hline \multirow{3}{*}{ S3 } & Exp. & 5 & 4.10 & 20.50 & 5.5 & \multirow{3}{*}{ Not Sig. } \\
\hline & Cont. & 5 & 6.90 & 34.50 & & \\
\hline & Total & 10 & & & & \\
\hline \multirow{3}{*}{ S4 } & Exp. & 5 & 5.10 & 25.50 & 10.5 & \multirow{3}{*}{ Not Sig. } \\
\hline & Cont. & 5 & 5.90 & 29.50 & & \\
\hline & Total & 10 & & & & \\
\hline \multirow{3}{*}{ S5 } & Exp. & 5 & 6.60 & 33.00 & 7 & \multirow{3}{*}{ Not Sig. } \\
\hline & Cont. & 5 & 4.40 & 22.00 & & \\
\hline & Total & 10 & & & & \\
\hline \multirow{3}{*}{ S6 } & Exp. & 5 & 6.00 & 30.00 & \multirow{3}{*}{10} & \multirow{3}{*}{ Not Sig. } \\
\hline & Cont. & 5 & 5.00 & 25.00 & & \\
\hline & Total & 10 & & & & \\
\hline \multirow{3}{*}{ S7 } & Exp. & 5 & 5.10 & 25.50 & \multirow{3}{*}{10.5} & \multirow{3}{*}{ Not Sig. } \\
\hline & Cont. & 5 & 5.90 & 29.50 & & \\
\hline & Total & 10 & & & & \\
\hline \multirow{3}{*}{ Total } & Exp. & 5 & 5.40 & 27.00 & \multirow{3}{*}{12} & \multirow{3}{*}{ Not Sig. } \\
\hline & Cont. & 5 & 5.60 & 28.00 & & \\
\hline & Total & 10 & & & & \\
\hline
\end{tabular}


Table 5: Results of the Mann-Whitney test of the CL in reading Scale

\begin{tabular}{|c|c|c|c|c|c|c|}
\hline & Group & $\mathbf{N}$ & $\begin{array}{l}\text { Mean } \\
\text { Rank } \\
\end{array}$ & $\begin{array}{c}\text { Sum of } \\
\text { Ranks }\end{array}$ & $\begin{array}{c}\text { Mann- } \\
\text { Whitney U }\end{array}$ & Sig. (2-tailed \\
\hline \multirow{3}{*}{ IL } & 1 & 5 & 5.80 & 29.00 & 11 & \multirow{3}{*}{ Not Sig. } \\
\hline & 2 & 5 & 5.20 & 26.00 & & \\
\hline & Total & 10 & & & & \\
\hline \multirow{3}{*}{ EL } & 1 & 5 & 5.90 & 29.50 & 10.5 & \multirow{3}{*}{ Not Sig. } \\
\hline & 2 & 5 & 5.10 & 25.50 & & \\
\hline & Total & 10 & & & & \\
\hline \multirow{3}{*}{ GL } & 1 & 5 & 5.80 & 29.00 & 11 & \multirow{3}{*}{ Not Sig. } \\
\hline & 2 & 5 & 5.20 & 26.00 & & \\
\hline & Total & 10 & & & & \\
\hline \multirow{3}{*}{$\mathrm{CL}$} & 1 & 5 & 5.90 & 29.50 & \multirow{3}{*}{10.5} & \multirow{3}{*}{ Not Sig. } \\
\hline & 2 & 5 & 5.10 & 25.50 & & \\
\hline & Total & 10 & & & & \\
\hline
\end{tabular}

* IL: Internal Load; EL: Extraneous Load; GL: Germane Load; CL: Cognitive Load-referring to the total cognitive load.

Results in tables 4 and 5 indicate that the values of $U$ were not statistically significant; in other words the differences in reading comprehension skills and cognitive load in reading between the control and experimental groups were not statistically significant. This meant that the two groups were equal in their level in reading comprehension and cognitive load while reading and that the differences that might occur between them after treatment could be attributed to the effect of the treatment itself.

\section{Procedures of the Study:}

In order to answer the questions of the study, the researchers followed certain procedures. To answer the first question of the study; "What are the design standards of the virtual environment based on DAISY technology for developing EFL reading comprehension skills of preparatory stage VI pupils and reducing their cognitive overload?" , a standards checklist was designed and structured as mentioned in the instruments section of the current study.

To answer the second question of the study; "What is the instructional design of a virtual environment based on DAISY technology for developing EFL reading comprehension skills of preparatory stage VI pupils and reducing their cognitive overload?", a virtual environment based on DAISY technology was designed as described in detail in the following section:

Design and Production of the Experimental DAISY-Based Virtual Environment:

The design of the virtual environment had undergone several 
systematic steps identified by the instructional design models across the web. Because the current research aims at developing reading comprehension skills, reducing the cognitive load of the visuallyimpaired pupils at the preparatory stage through designing the virtual environment, the researchers analyzed a number of instructional design models to identify the most important stages and steps to be followed in designing the environment. The Ryan et al. (2000) model, Ruffini (2000) model, Ismail (2009) model, and El Gazzar (2014) model were the major models to be made use of. In addition, Khamis's (2009) advanced model was adapted by the researchers with some modifications to suit the nature of the present research as it provides a comprehensive description of all design and instructional development processes. The design process was carried out according to the following procedures:

\section{1- Analysis Phase: This stage was} not only one of the most important stages in designing a virtual environment, but also the basis for any electronic learning environment. This stage includes a set of steps that can be clarified as follows:

- Educational Needs Analysis: The aim of this step was to assess the educational needs of the visuallyimpaired pupils at the preparatory stage, and formulate them in the form of general goals describing the desired achievement by the end of the learning process. The educational needs of the research sample were set to identify their knowledge and skills in order to determine which skills to develop. Moreover, the cognitive load generated as a result of the reading process and the tasks required to be answered after each reading passage was considered. Therefore, the present study sought to develop reading comprehension skills and to reduce the cognitive load of the visually- impaired pupils.

- Learning Task Analysis: The educational tasks are represented in the cognitive concepts, reading comprehension skills, reducing the cognitive load during reading. These tasks were analyzed, divided, and arranged in a hierarchical form that shows how to learn. The overall objectives were identified and analyzed to detailed levels. The final tasks could be identified and elaborated as follows:

A. Final Tasks: The two researchers analyzed reading comprehension skills and identified the targeted skills necessary for targeted pupils, and determined the requirements and means for reducing the cognitive load of the visually- impaired pupils that align with the principles of the cognitive load theory.

B. Elaborating constituent tasks: The researchers used the hierarchical approach in 
breaking down the educational tasks into subtasks and then dividing the latter into other subtasks, using the appropriate educational analysis of the nature of the reading comprehension tasks, taskrelated requirements and conditions that lead to reducing the cognitive overload, and of the characteristics of the research sample.

- Analysis of learner characteristics: Learners are the target group of the proposed virtual environment; therefore, design processes should be centered around learners' needs and characteristics. Analysis of the characteristics of the target learners is useful for determining:

- Level of educational experiences, and selecting the level of activities and examples appropriate for them.

- Selecting the appropriate teaching and learning strategies for them.

- Selecting the level and type of interaction with different learning sources.

Design of the Environment should be done in accordance with the students' prior knowledge of the subject they will be learning, identifying the basic skills that must be learned first, their previous learning methods and experiences, and their motivation to learn. Some studies have shown that the visually impaired children suffer from problems such as isolation, introversion, shyness, forgetfulness, and inability to concentrate for a long time, leading to poor attention and thus reduced ability to link together subjects across the curriculum, resulting in a lack of reading comprehension skills and increased cognitive load in learning. Therefore, the researchers designed a virtual environment that employs DAISY technology to develop reading comprehension skills and reduce their cognitive load.

- Analysis of the learning environment: An analysis of resources and constraints has been undertaken to identify educational and human capabilities that facilitate design, development, use and evaluation processes.

2- Design phase: This stage included the following steps:

- Developing Instructional design standards for the virtual learning environment for the visuallyimpaired students: through analyzing previous literature and studies, identifying the preliminary checklist, and presenting the checklist to a group of experts in educational technology for validation and making the necessary modifications.

- Setting learning objectives: This was an essential step in the design phase, then analyzing the content and extracting the concepts and skills involved which should be 
mastered by the learners by the end of the learning process in a relatively specific period, followed by the formulation of content in its final form, so the learner must be able to:

o Skim the text for the main idea.

o Scan the text for specific details.

o Guess the meaning of difficult words from context.

o Predict what the text will be about.

○ Infer implicit information.

o Extract important points to summarize the text.

- Recognize relationships among sentences in the text.

- Content analysis and organization: It has gone through the following steps:

1. Specifying the content: three units from the English language textbook "New Hello, year twofirst term" for the preparatory stage were selected: Module three: units $7,8 \&$ 9. The reading comprehension skills for the visually- impaired pupils were identified to determine the best sequence of content structure, identify the previous requirements, choose the appropriate learning style for each student in the research sample.

2. Organizing the content: The organization of the content is closely related to the map of task analysis, so the elements of the content were identified, organized and arranged in a logical sequence similar to the scenario, starting the learning process from the simplest levels to achieve the intended goals, through the various interactions and the evaluation process.

3. Determining the learning strategy: The researchers used the individual learning strategy according to each student's selfprogress in the virtual environment that employs DAISY technology where the learner is actively engaged in learning through his knowledge of the program, navigating within the virtual environment, practicing activities, and being tested independently. The content is presented with explanations, examples, and voice commentary, allowing the learner to use multimedia more than once, and providing diverse learning resources for the learner to use.

- Identifying assistance and guidance tools: Each student was encouraged to participate and reactivate their responses by identifying activities and exercises after performing each task, providing guidance and assistance through synchronous and asynchronous communication tools with the teacher, feedback, and also by the instructions in the environment. 
- Selection and/or design of learning resources: They represented all the resources where the pupil can obtain a piece of information; and they may not be available or ready. Therefore, the researchers compiled open-source learning resources such as dictionaries and thesauruses, which the visuallyimpaired pupils can benefit from without being restricted. Some other sources such as the audio files were designed by the researches.

- Designing user interface: Virtual Environment Interaction interfaces were designed to include several elements, namely the program, bulletin board, discussion topics, chat room, learning resources, e-mail, and teacher page.

3- Development phase: The researchers at this stage carried out the following steps:

- Script writing: A diagram of the shape and components of the virtual environment and its content was prepared, making it easy to create coherent virtual environment, in accordance with the DAISY Technology. The outlines were translated into detailed procedures, real educational events and situations on paper to describe the environment and interaction interfaces with the user including the subdivisions, taking into account what was prepared and equipped in the design stage to identify the audio elements of the multimedia through the provision of texts, and voice comments to explain some elements and clarify them.

- Flow Map Design: The researchers determined the relationships among pieces of information. The flow chart was designed in the form of an integrated diagram of symbols and geometric shapes to illustrate the method of navigation and interaction in the virtual environment. The following diagram shows the flow chart of the virtual environment: 
Figure 3: The Flowchart of the Virtual Environment Design

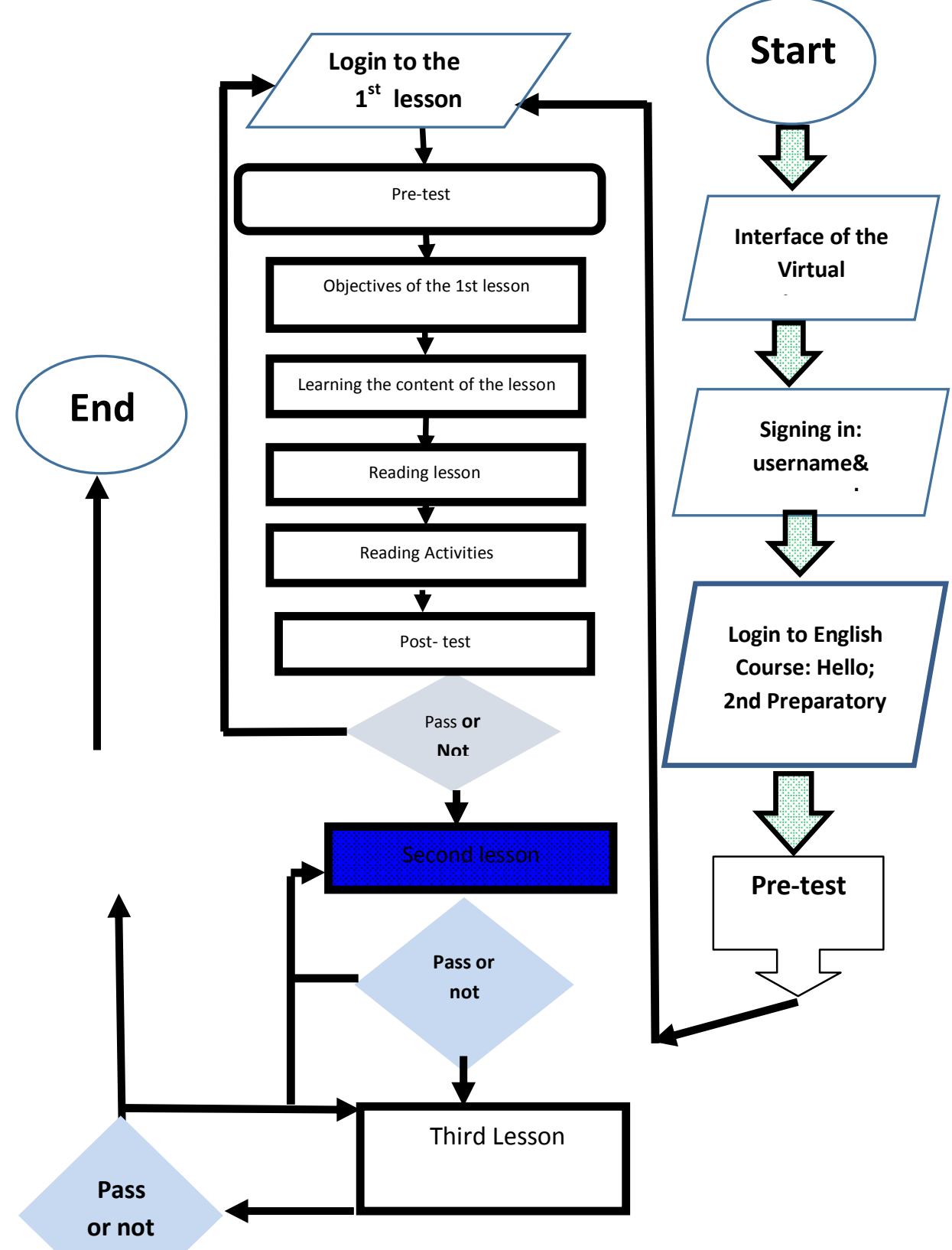


- Digitizing educational content elements: The scenario was transformed into a virtual environment that was based on DAISY technology to suit the needs and characteristics of the participants.

- Formative assessment of the initial form of the virtual learning environment: After the production of the environment, it was presented to a group of experts in the field of educational technology to express opinion in its design, content, and steps. The necessary modifications were made to reach the final form of the environment.

- Final output of the environment: After carrying out the modifications recommended by the experts, the final form of the environment was prepared.

- Development of the learning environment tools within the system: Moodle system was used as an open- source learning management system (LMS) to manage the virtual learning environment that employed DAISY technology.

\section{4- Evaluation and approval phase:}

At this stage, the environment was checked and verified by applying it to a pilot sample other than the main sample of the study (represented in). After piloting the environment, the necessary modifications were made to make the environment suitable for the final application. In addition, there was an educational, technical and technological review through presenting the environment to educational technology specialists to validate it.

Finally, the virtual environment based on DAISY technology for developing reading comprehension skills of visually- impaired pupils at the preparatory stage and reducing their cognitive load was ready for implementation.

The treatment (Application):

Aim of the treatment:

This treatment aimed at developing the EFL speaking skills and self-efficacy of visually impaired pupils at the preparatory stage. To achieve that aim, speaking activities based on the multiple intelligences theory (MIT) were designed and implemented in the EFL classroom.

\section{Objectives of the treatment:}

By the end of the proposed

treatment, pupils should be able to:

1. Skim the text for the main idea.

2. Scan the text for specific details.

3. Guess the meaning of difficult words from context.

4. Predict what the text will be about.

5. Infer implicit information.

6. Extract important points to summarize the text.

7. Recognize relationships among sentences in the text.

\section{Content and duration of the treatment:}

The treatment was applied during the second term of the academic year 2018/2019. The content was divided into 8 sessions, each session lasted for forty five minutes in addition to two sessions for the pre- and postadministrations of the instruments of 
the study. During each session the pupils practiced the predetermined reading comprehension sub-skills through the designed environment.

The main premise underlying instruction in the proposed virtual DAISY- based environment was using audio- supported reading (ASR) with integrated tasks and questions that facilitate comprehension for the visuallyimpaired pupils based on the principles of cognitive load theory. For example, extraneous cognitive load was decreased based on the "modality effect", which suggests that it is possible to decrease extraneous load on working memory by using more than one mode of communication- both visual and auditory. Evidence suggests that working memory can be subdivided into auditory and visual streams, so presenting information using both auditory and visual working memory can increase working memory capacity. Using both auditory and visual channels increases the capacity of working memory, and facilitates more effective learning (Jeung, Chandler\& Sweller 1997; Mousavi, Low\& Sweller 1995; Tindall-Ford, Chandler\& Sweller 1997).

Proposed activities within the virtual environment were based also on the objectives of the lesson, functions to be mastered in each lesson, the principles of cognitive load reduction instruction, and the content of each lesson. The activities were applied throughout the whole lesson whenever possible; including warm-up activities, pre-reading, while- reading and post- reading activities.
Various instructional aids and supplementary materials were used in accordance with the proposed environment. Audio materials such as short stories and songs were made use of wherever possible and suitable within the stages of reading. In addition, handouts in Braille and tactile models were also used.

\section{Assessment \& Evaluation:}

The assessment procedures integrated in the treatment composed of both formative and summative assessment. Formative assessment aimed at assessing learners' gradual progress in reading comprehension through integrated tasks within each lesson such as asking questions or getting pupils to report their understanding through summarizing the text. Necessary feedback on the pupils' overall reading performance was provided at the end of each lesson.

The second type of assessment was summative. This was conducted at the end of the application of the treatment. It included the administration of the EFL reading comprehension test. Its purpose was to measure the achievement of the targeted goals at the end of the treatment application. Namely; it aimed at investigating the effectiveness of the proposed DAISY-based virtual environment in developing second year preparatory stage visually- impaired pupils' reading comprehension skills and reducing their cognitive overload while reading.

\section{Results and Discussion:}

Results:

The results of the study will be presented in terms of the study hypotheses as follows: 
Hypothesis one: "There is a statistically significant difference at (0.05) level between the mean ranks of the experimental and control group pupils' scores on the postadministration of the reading comprehension skills test in favor of the experimental group".

In order to test the first hypothesis, the researchers used "Mann-Whitney Test" for independent groups in the case of non-parametric statistics (as the sample of the study consisted of five participants in each group $(\mathrm{N}=10$ 30) to identify the significance of differences between the mean rank scores of the experimental and control groups students on the postadministration of the Reading Comprehension test. The following table illustrates (U) values for the differences between the mean rank scores and their statistical significance.

Table 6: Results of Mann-Whitney test of the control and experimental groups on the post-administration of the Reading Comprehension test

\begin{tabular}{|c|c|c|c|c|c|c|}
\hline Skills & Group & $\mathbf{N}$ & $\begin{array}{l}\text { Mean } \\
\text { Rank } \\
\end{array}$ & $\begin{array}{c}\text { Sum of } \\
\text { Ranks }\end{array}$ & Mann-Whitney U & Sig. (2-tailed \\
\hline \multirow{3}{*}{ S1 } & Exp. & 5 & 7.40 & 37.00 & 3 & \multirow{3}{*}{$\begin{array}{c}\text { Significant at } \\
0.05\end{array}$} \\
\hline & Cont. & 5 & 3.60 & 18.00 & & \\
\hline & Total & 10 & & & & \\
\hline \multirow{3}{*}{$\mathbf{S 2}$} & Exp. & 5 & 8.00 & 40.00 & 0 & \multirow{3}{*}{$\begin{array}{c}\text { Significant at } \\
0.05\end{array}$} \\
\hline & Cont. & 5 & 3.00 & 15.00 & & \\
\hline & Total & 10 & & & & \\
\hline \multirow{3}{*}{ S3 } & Exp. & 5 & 7.80 & 39.00 & 1 & \multirow{3}{*}{$\begin{array}{c}\text { Significant at } \\
0.05\end{array}$} \\
\hline & Cont. & 5 & 3.20 & 16.00 & & \\
\hline & Total & 10 & & & & \\
\hline \multirow{3}{*}{ S4 } & Exp. & 5 & 7.50 & 37.50 & 2.5 & \multirow{3}{*}{$\begin{array}{c}\text { Significant at } \\
0.05\end{array}$} \\
\hline & Cont. & 5 & 3.50 & 17.50 & & \\
\hline & Total & 10 & & & & \\
\hline \multirow{3}{*}{ S5 } & Exp. & 5 & 7.80 & 39.00 & 1 & \multirow{3}{*}{$\begin{array}{c}\text { Significant at } \\
0.05\end{array}$} \\
\hline & Cont. & 5 & 3.20 & 16.00 & & \\
\hline & Total & 10 & & & & \\
\hline \multirow{3}{*}{ S6 } & Exp. & 5 & 7.90 & 39.50 & 0.5 & \multirow{3}{*}{$\begin{array}{c}\text { Significant at } \\
0.05\end{array}$} \\
\hline & Cont. & 5 & 3.10 & 15.50 & & \\
\hline & Total & 10 & & & & \\
\hline \multirow{3}{*}{ S7 } & Exp. & 5 & 8.00 & 40.00 & 0 & \multirow{3}{*}{$\begin{array}{c}\text { Significant at } \\
0.05\end{array}$} \\
\hline & Cont. & 5 & 3.00 & 15.00 & & \\
\hline & Total & 10 & & & & \\
\hline \multirow{3}{*}{$\begin{array}{l}\text { Total } \\
\text { score }\end{array}$} & Exp. & 5 & 8.00 & 40.00 & 0 & \multirow{3}{*}{$\begin{array}{c}\text { Significant at } \\
0.05\end{array}$} \\
\hline & Cont. & 5 & 3.00 & 15.00 & & \\
\hline & Total & 10 & & & & \\
\hline
\end{tabular}


Results in table 6 indicate that the mean rank scores of the experimental group pupils on the post- administration of the Reading Comprehension test were less than those of the control group pupils, both in the seven component subskills and the overall reading comprehension skill. The values of $U$ were significant at (0.05) level of significance. This means that there were statistically significant differences between the mean rank scores of the experimental and control groups pupils on the postadministration of the Reading Comprehension test in favor of the experimental group. Consequently, the first hypothesis was accepted.

Results obtained from applying Mann Whitney test concerning the differences between the mean rank scores of the experimental and control groups pupils on the postadministration of the Reading Comprehension test can be illustrated through the following figure:

Figure 4: Differences between the mean rank scores of the experimental and control groups pupils on the post- administration of the Reading Comprehension test

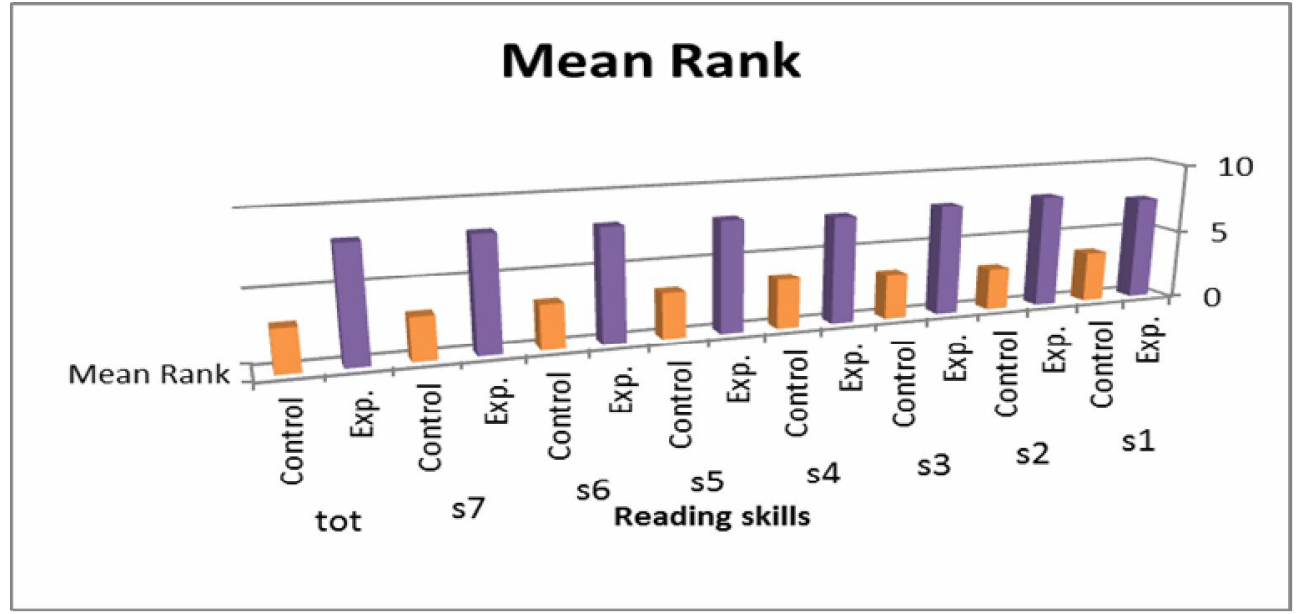

Hypothesis two: "There is a statistically significant difference at (0.05) level between the mean ranks of the experimental group pupils' scores on the pre- and postadministrations of the reading comprehension test in favor of the post- administration".

In order to verify the second hypothesis, the researchers used
"Wilcoxon Test" for related groups in the case of non-parametric statistics. The following table illustrates (Z) values and their statistical significance for the differences between the mean rank scores of the experimental group pupils on the pre- and postadministrations of the reading comprehension test. The following table illustrated the results of the Wilcoxon test. 
Table 7: Results of Wilcoxon Signed Ranks-test of the experimental group on the pre-post-administrations of the Reading Comprehension test

\begin{tabular}{|c|c|c|c|c|c|c|c|c|}
\hline & Ranks & $\mathbf{N}$ & $\begin{array}{l}\text { Mean } \\
\text { Rank }\end{array}$ & $\begin{array}{c}\text { Sum of } \\
\text { Ranks }\end{array}$ & $\mathbf{Z}$ & $(\eta 2)^{*}$ & $\begin{array}{c}\text { Effect } \\
\text { size }\end{array}$ & $\begin{array}{l}\text { Sig. }(2- \\
\text { tailed })\end{array}$ \\
\hline \multirow{4}{*}{ S1 } & Negative Ranks & 0 & .00 & .00 & \multirow{4}{*}{2.032} & \multirow{4}{*}{0.91} & \multirow{4}{*}{ high } & \multirow{4}{*}{$\begin{array}{l}\text { Significa } \\
\text { nt at } 0.05\end{array}$} \\
\hline & Positive Ranks & 5 & 3.00 & 15.00 & & & & \\
\hline & Ties & 0 & & & & & & \\
\hline & Total & 5 & & & & & & \\
\hline \multirow{4}{*}{ S2 } & Negative Ranks & 0 & .00 & .00 & \multirow{4}{*}{2.060} & \multirow{4}{*}{0.92} & \multirow{4}{*}{ high } & \multirow{4}{*}{$\begin{array}{l}\text { Significa } \\
\text { nt at } 0.05\end{array}$} \\
\hline & Positive Ranks & 5 & 3.00 & 15.00 & & & & \\
\hline & Ties & 0 & & & & & & \\
\hline & Total & 5 & & & & & & \\
\hline \multirow{4}{*}{ S3 } & Negative Ranks & 0 & .00 & .00 & \multirow{4}{*}{2.060} & \multirow{4}{*}{0.92} & \multirow{4}{*}{ high } & \multirow{4}{*}{$\begin{array}{l}\text { Significa } \\
\text { nt at } 0.05\end{array}$} \\
\hline & Positive Ranks & 5 & 3.00 & 15.00 & & & & \\
\hline & Ties & 0 & & & & & & \\
\hline & Total & 5 & & & & & & \\
\hline \multirow{4}{*}{ S4 } & Negative Ranks & 0 & .00 & .00 & \multirow{4}{*}{2.03} & \multirow{4}{*}{0.908} & \multirow{4}{*}{ high } & \multirow{4}{*}{$\begin{array}{l}\text { Significa } \\
\text { nt at } 0.05\end{array}$} \\
\hline & Positive Ranks & 5 & 3.00 & 15.00 & & & & \\
\hline & Ties & 0 & & & & & & \\
\hline & Total & 5 & & & & & & \\
\hline \multirow{4}{*}{ S5 } & Negative Ranks & 0 & .00 & .00 & \multirow{4}{*}{2.121} & \multirow{4}{*}{0.95} & \multirow{4}{*}{ high } & \multirow{4}{*}{$\begin{array}{l}\text { Significa } \\
\text { nt at } 0.05\end{array}$} \\
\hline & Positive Ranks & 5 & 3.00 & 15.00 & & & & \\
\hline & Ties & 0 & & & & & & \\
\hline & Total & 5 & & & & & & \\
\hline \multirow{4}{*}{ S6 } & Negative Ranks & 0 & .00 & .00 & \multirow{4}{*}{2.12} & \multirow{4}{*}{0.95} & & \\
\hline & Positive Ranks & 5 & 3.00 & 15.00 & & & hich & Significa \\
\hline & Ties & 0 & & & & & $111 \mathrm{~g}$ & nt at 0.05 \\
\hline & Total & 5 & & & & & & \\
\hline & Negative Ranks & 0 & .00 & .00 & & & & \\
\hline S7 & Positive Ranks & 5 & 3.00 & 15.00 & 2041 & 001 & hioh & Significa \\
\hline 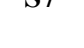 & Ties & 0 & & & 2.071 & 0.01 & II & nt at 0.05 \\
\hline & Total & 5 & & & & & & \\
\hline & Negative Ranks & 0 & .00 & .00 & & & & \\
\hline Total & Positive Ranks & 5 & 3.00 & 15.00 & 2023 & 0.0 & hioh & Significa \\
\hline Fotat & Ties & 0 & & & $2.02 J$ & & III & nt at 0.05 \\
\hline & Total & 5 & & & & & & \\
\hline
\end{tabular}


Results in the above table illustrate that the estimated $\mathrm{Z}$ value is significant at 0.05 level. This reflects that there were statistically significant differences between the mean rank scores of the pre- and post-administrations of the reading comprehension test in the seven component skills and in the total score. These significant differences were in favor of the postadministration. Thus, the first hypothesis was accepted.

Results in table 7 indicated that the effect size of the proposed treatment was high on the seven subskills as the value of ( $\boldsymbol{\eta} 2)$ ranged between (0.908) and (0.95). In addition, the value of ( $(\eta 2)$ for the effect size of the treatment on the overall EFL reading comprehension skill was (0.90), and this indicated a high effect size too. The difference between the pre- and postadministrations can be illustrated similarly that $(90 \%)$ of variance in the pupils' reading comprehension skills as a whole can be attributed to the implementation of the DAISYbased virtual environment. Concerning reading comprehension subskills; a percentage that ranged between $90.8 \%$ and $95 \%$ of variance in pupils' performance in relation to their reading comprehension subskills can be attributed to the effect of implementing the proposed DAISY-based virtual environment.

It is clear that the statistical differences between the pre- and postadministrations of EFL reading comprehension test were in favor of the post-administration. In addition, the size of these differences fosters the positive effect of the proposed environment on the pupils' reading comprehension. Therefore, the second hypothesis of the study was verified and accepted.

Hypothesis three: "There is a statistically significant difference at (0.05) level between the mean ranks of the experimental and control group pupils' scores on the postadministration of the cognitive load scale in favor of the experimental group.

In order to test the third hypothesis, the researchers used "Mann-Whitney Test" for independent groups in the case of nonparametric statistics (as the sample of the study consisted of five participants in each group $(\mathrm{N}=10$ - 30) to identify the significance of differences between the mean rank scores of the experimental and control groups students on the post- administration of the Cognitive Load in reading scale. The following table illustrates (U) values for the differences between the mean rank scores and their statistical significance. 
Table 8:Results of Mann-Whitney test of the control and experimental groups on the post-administration of the CL Scale

\begin{tabular}{|c|c|c|c|c|c|c|}
\hline & Group & $\mathbf{N}$ & Mean Rank & Sum of Ranks & Mann-Whitney U & Sig. (2tailed) \\
\hline \multirow{3}{*}{ IL } & Exp. & 5 & 3.30 & 16.50 & 1.5 & \multirow{3}{*}{$\begin{array}{c}\text { Significant a } \\
0.05\end{array}$} \\
\hline & Cont. & 5 & 7.70 & 38.50 & & \\
\hline & Total & 10 & & & & \\
\hline \multirow{3}{*}{ EL } & Exp. & 5 & 3.10 & 15.50 & 0.5 & \multirow{3}{*}{$\begin{array}{c}\text { Significant at } \\
0.05\end{array}$} \\
\hline & Cont. & 5 & 7.90 & 39.50 & & \\
\hline & Total & 10 & & & & \\
\hline \multirow{3}{*}{ GL } & Exp. & 5 & 3.00 & 15.00 & 0 & \multirow{3}{*}{$\begin{array}{c}\text { Significant a } \\
0.05\end{array}$} \\
\hline & Cont. & 5 & 8.00 & 40.00 & & \\
\hline & Total & 10 & & & & \\
\hline \multirow{3}{*}{ CL } & Exp. & 5 & 3.00 & 15.00 & 0 & \multirow{3}{*}{$\begin{array}{c}\text { Significant at } \\
0.05\end{array}$} \\
\hline & Cont. & 5 & 8.00 & 40.00 & & \\
\hline & Total & 10 & & & & \\
\hline
\end{tabular}

* IL: Internal Load; EL: Extraneous Load; GL: Germane Load; CL: Cognitive Load- referring to the total cognitive load.

Results in table 8 indicate that the mean rank scores of the experimental group pupils on the post- administration of the Cognitive Load in reading scale were less than those of the control group pupils, both in the three component types of cognitive load and the total cognitive load in reading. The values of $U$ were significant at (0.05) level of significance. This means that there were statistically significant differences between the mean rank scores of the experimental and control group pupils on the post administration of the Cognitive Load in reading scale in favor of the experimental group. Consequently, the third hypothesis was accepted. The obtained results can be illustrated through the following figure:

Figure5: Differences between the mean rank scores of the experimental and control groups pupils on the post-administration of the Reading Comprehension test

\section{Mean Rank}

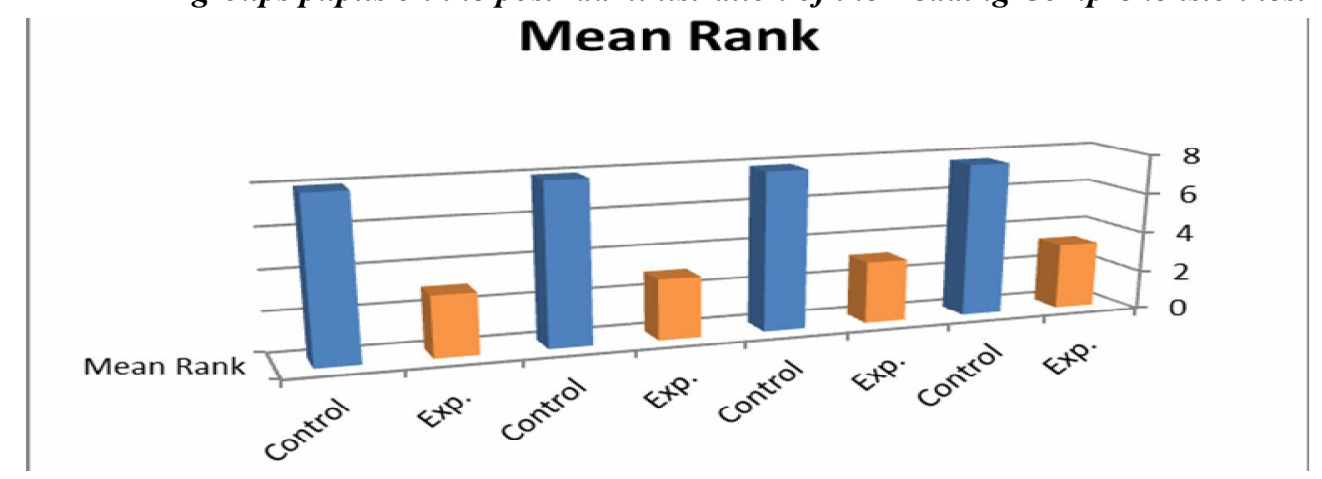


Hypothesis four: "There is a statistically significant difference at (0.05) level between the mean ranks of the experimental group pupils' scores on the pre- and postadministrations of the cognitive load scale in favor of the postadministration.".

In order to verify the fourth hypothesis, the researchers used
"Wilcoxon Test" for related groups in the case of non-parametric statistics. The following table illustrates $(Z)$ values and their statistical significance for the differences between the mean rank scores of the experimental group pupils on the pre- and postadministrations of the $\mathrm{CL}$ in reading scale.

Table 9: Results of Wilcoxon Signed Ranks-test of the experimental group on the pre- and post-administrations of the CL in reading Scale

\begin{tabular}{|c|c|c|c|c|c|c|c|c|}
\hline & Ranks & $\mathbf{N}$ & $\begin{array}{l}\text { Mean } \\
\text { Rank } \\
\end{array}$ & $\begin{array}{c}\text { Sum of } \\
\text { Ranks }\end{array}$ & $\mathbf{Z}$ & $(\eta 2)^{*}$ & $\begin{array}{c}\text { effect } \\
\text { size }\end{array}$ & $\begin{array}{l}\text { Sig. }(2- \\
\text { tailed) }\end{array}$ \\
\hline \multirow{4}{*}{ IL } & $\begin{array}{c}\text { Negative } \\
\text { Ranks }\end{array}$ & 5 & 3.00 & 15.00 & \multirow{4}{*}{2.032} & \multirow{4}{*}{0.91} & \multirow{4}{*}{ high } & \multirow{4}{*}{$\begin{array}{l}\text { Sig. } \\
0.05\end{array}$} \\
\hline & $\begin{array}{c}\text { Positive } \\
\text { Ranks }\end{array}$ & 0 & .00 & .00 & & & & \\
\hline & Ties & 0 & & & & & & \\
\hline & Total & 5 & & & & & & \\
\hline \multirow{4}{*}{ EL } & $\begin{array}{c}\text { Negative } \\
\text { Ranks }\end{array}$ & 5 & 3.00 & 15.00 & \multirow{4}{*}{2.023} & \multirow{4}{*}{0.90} & \multirow{4}{*}{ high } & \multirow{4}{*}{$\begin{array}{l}\text { Sig. } \\
0.05\end{array}$} \\
\hline & $\begin{array}{c}\text { Positive } \\
\text { Ranks }\end{array}$ & 0 & .00 & .00 & & & & \\
\hline & Ties & 0 & & & & & & \\
\hline & Total & 5 & & & & & & \\
\hline \multirow{4}{*}{ GL } & $\begin{array}{c}\text { Negative } \\
\text { Ranks }\end{array}$ & 5 & 3.00 & 15.00 & \multirow{4}{*}{2.032} & \multirow{4}{*}{0.91} & \multirow{4}{*}{ high } & \multirow{4}{*}{$\begin{array}{l}\text { Sig. } \\
0.05\end{array}$} \\
\hline & $\begin{array}{c}\text { Positive } \\
\text { Ranks }\end{array}$ & 0 & .00 & .00 & & & & \\
\hline & Ties & 0 & & & & & & \\
\hline & Total & 5 & & & & & & \\
\hline \multirow{4}{*}{ CL } & $\begin{array}{c}\text { Negative } \\
\text { Ranks }\end{array}$ & 5 & 3.00 & 15.00 & \multirow{4}{*}{2.023} & \multirow{4}{*}{0.90} & \multirow{4}{*}{ high } & \multirow{4}{*}{$\begin{array}{l}\text { Sig. } \\
0.05\end{array}$} \\
\hline & $\begin{array}{c}\text { Positive } \\
\text { Ranks }\end{array}$ & 0 & .00 & .00 & & & & \\
\hline & Ties & 0 & & & & & & \\
\hline & Total & 5 & & & & & & \\
\hline
\end{tabular}


It is clear that the value of $(\mathrm{Z})$ for the total cognitive load in reading (2.392) was statistically significant at (0.05) level of significance in favor of the post-administration of the CL in reading scale. This indicates that there was a statistically significant difference between the mean ranks of the experimental group pupils' scores on the pre- and post- administrations of the CL in reading scale in favor the post-administration. This proved that the proposed treatment lead to reducing the cognitive load in reading for the experimental group pupils. Thus, the fourth hypothesis was accepted.

Results in table 9 indicated that the effect size of the proposed treatment was high on the three types of cognitive load as the value of ( $\mathbf{\eta} \mathbf{2})$ was $(0.91), \quad(0.90)$ and(0.91) respectively. In addition, the value of (n2) for the effect size of the treatment on the overall cognitive load in reading was $(0.90)$, and this indicated a high effect size too. The difference between the pre- and postadministrations can be illustrated similarly that $(90 \%)$ of variance in the pupils' cognitive load as a whole can be attributed to the proposed experimental treatment. Concerning the three types of cognitive load; a percentage that ranged between $90 \%$ and $91 \%$ of variance in pupils' cognitive load in reading can be attributed to the effect of implementing the proposed DAISYbased virtual environment. All in all, it could be interpreted that the DAISY- based virtual environment was effective in reducing the cognitive load in reading for the experimental group pupils.

\section{Discussion:}

The current study attempted to investigate the effectiveness of implementing a DAISY- based virtual environment for developing EFL reading comprehension skills and reducing cognitive load in reading of the visually impaired pupils at the preparatory stage. The results revealed a statistically significant difference between the mean ranks of the experimental group pupils' scores and those of the control group on the post- administration of the reading comprehension test in favor of the experimental group. Furthermore, there was a statistically significant difference between the mean ranks of the experimental group pupils' scores on the pre- and post- administrations of the reading comprehension test in favor of the post- administration. The difference is apparent in both the total score of the test and the scores of the sub-skills combined in the speaking test. This means that visually impaired pupils' reading comprehension skills improved as a result of applying the proposed DAISY- based virtual environment in the EFL reading Classroom.

The present study provided evidence for the effectiveness of using a DAISY-based virtual environment in developing second year preparatory stage pupils' EFL reading comprehension skills. It is consistent with the results of similar studies on reading comprehension of the VI 
(Gunarhadi\& Sunardi, 2017; McLaughlin\& Kamei-Hannan, 2018). The reached results could be attributed to the design of the virtual environment that addressed pupils' needs, strengths and areas of interest.

The DAISY- based virtual environment considered the nature of the visually impaired, and was designed in the light of the principles of cognitive load theory hand in hand with the most suitable procedures for developing reading comprehension skills of the visually impaired pupils at the preparatory stage. It also created an enjoyable atmosphere in the classroom, away from the daily routine of traditional practices in the EFL lessons.

Further, the current study proved that there was a statistically significant difference at (0.05) level between the mean ranks of the experimental group pupils' scores and those of the control group pupils on the post- administration of the cognitive load in reading scale favoring the experimental group. Moreover, there was a statistically significant difference at (0.05) level between the mean ranks of the experimental group pupils' scores on the pre- and post- administrations of the cognitive load in reading scale in favor of the post- administration; as their additive cognitive load was reduced on the post- administration of the scale.

The results of the current study related to cognitive load are consistent with those of previous studies such as Yu (2002), Hung (2009), Al-Shehri and Gitaski (2010).This result could be interpreted in the light of the adapted design of the environment and the reading activities where the principles of cognitive load theory were taken into consideration. It is acknowledged that unnecessary cognitive load; namely intrinsic and extraneous, could be reduced through adaptations made to the material and tasks, and the procedures of implementing learning activities. For example, evidence suggests that working memory can be subdivided into auditory and visual streams, so presenting information using both auditory and visual working memory can increase working memory capacity. Using both auditory and visual channels increases the capacity of working memory, and facilitates more effective learning (Jeung, Chandler\& Sweller 1997; Mousavi, Low\& Sweller 1995; Tindall-Ford, Chandler\& Sweller 1997).

Generally, pupils who participated in the study expressed their satisfaction with the activities; they found them different, encouraging, interesting, and sometimes challenging to a degree that ignited their motivation to succeed and achieve their goals. They were satisfied with their overall performance during the experiment as they felt successful, cooperative and supportive for each other.

\section{Conclusions:}

The current study aimed at investigating the effectiveness of designing a virtual environment based on DAISY technology in EFL classes 
for developing the reading comprehension skills and reducing cognitive load of visually- impaired pupils at the preparatory stage. The results demonstrated a significant difference between the pre- and postadministrations of the reading comprehension test and the cognitive load scale; tools of the study. This implies that the proposed virtual environment was effective in developing the specified EFL reading comprehension skills and reducing the cognitive overload of second year prep stage visually- impaired pupils.

The findings of the current study suggest that EFL teachers of the visually impaired should be creative and try hard to provide an instructional environment that is supportive and encouraging for those pupils; such an environment that builds upon their strengths and extend to polish their skills and strengthen their positive beliefs about themselves.

The findings also suggest that Cognitive load theory is useful in directing EFL instructional practices where many basic principles could be considered and employed for developing various language skills of the visually impaired.

\section{Recommendations:}

In the light of the results of the current study the following recommendations are suggested:

- Special education curriculum designers should pay adequate attention towards the necessity of adapting VI EFL textbooks to suit their visual impairment and exploit their remain senses and magnify their skills.

- EFL curriculum planners should pay sufficient attention towards the importance of integrating assistive technology in EFL curriculum, especially for the VI pupils.

- EFL teachers of the VI should adapt their teaching practices to suit the needs of their pupils through implementing suitable technological applications in their classes to develop several language skills.

- Researchers in the field of EFL for special education in general and for VI pupils in particular, should exert tremendous efforts for tackling the language issues related to this field; as this field is currently, although very important, still under- researched.

\section{Suggestions for further research:}

In the light of results and recommendations proposed by the current study, the following research topics are suggested:

- The effectiveness of a DAISYbased program in developing EFL listening skills of the visually impaired pupils at different educational stages (primary, preparatory, secondary).

- The effect of implementing DAISY technology in developing EFL oral communication skills and enhancing self-esteem for visually impaired pupils at the preparatory stage. 
- Using DAISY technology for developing vocabulary learning of VI pupils at different educational stages.

- The effectiveness of using Multisensory enrichment activities for developing EFL reading comprehension skills for the visually impaired pupils at the preparatory stage.

- Using cognitive load theory as a directive for designing teaching practices that could optimize students' learning in the context of mainstream and special education

\section{References}

1. Al-Shehri, S., and Gitsaki, C. (2010). Online reading: a preliminary study of the impact of integrated and split-attention formats on L2 students' cognitive load. ReCALL, 22(3), 356-375.

2. Artino, A. (2008). Cognitive load theory and the role of learner experience: An abbreviated review of educational practitioners. Association for the Advancement of Computing in Education Journal, 16(4), 425439.

3. Atasi, M. \&Madanmohan, S. (2008). Learning Through Virtual Classroom. Accessed at http://www.aiaer.net/ejournal/V ol19207/24.Atasi Madan.htm

4. Ayoku, F.A. (2006) (Ed.). The visually impaired in the regular classroom. Obani. T.C.
5. Ayres, P. (2006). Impact of reducing intrinsic cognitive load on learning in a mathematical domain. Applied Cognitive Psychology, 20, 287-298.

6. Başaran, S. (2012). Teaching English to visually impaired students in Turkey: A case study. Energy Education Science and Technology Part B: Social and Educational Studies, Special Issue 2: 217-226.

7. Blackorby, J., Chorost, M., Garza, N.\& Guzman, A. (2003). The academic performance of secondary students with disabilities. Available at: www.nlts2.org/pdfs'achievemen ts-ch4.pdf.

8. Centre for Education, Statistics and Evaluation (2017). Cognitive load theory: Research that teachers really need to understand. NSW Department of Education, Sydney, Australia.

9. Chandler, P.\& Sweller, J. (1991). Cognitive Load Theory and the Format of Instruction. Cognition and Instruction, 8(4), 293-332.

10. Christidou, S. (2016). Foreign Language Learning for the Visually Impaired in the Region of Central Macedonia, Greece: Problems and Suggestions. USChina Foreign Language, 14 (3), 214-226.

11. Cooper, G. (1998). Research into cognitive load theory and instructional design at UNSW. Retrieved from 
http://www.arts.unsw.edu.au/ed ucation/CLT_NET_Aug_97.HT ML

12. Daisy Consortium. (2007). Daisy tools. Available at: http://www.daisy.org/tools/579

13. Davis, P. (2003). Including Children with Visual Impairment to the Mainstream Schools. London: David Fulton Publishers.

14. Douglas, G., Grimley, M., Hill, E., Long, R.\& Tobin, M. (2002). The Use of the NARA for Assessing the Reading Ability of Children with Low Vision. British Journal of Visual Impairment, 20: 68-75.

15. Elliott, S., Kurz, A., Beddow, P. \& Frey, J. (2009). Cognitive Load Theory: Instruction-based Research with Applications for Designing Tests. Paper Presented at the National Association of School Psychologists' Annual Convention: Boston, MA.

16. Esteves, K.J. (2007). Audioassisted reading with digital audiobooks for upper elementary students with reading disabilities. Ph.D. Thesis, Western Michigan University, Kalamazoo.

17. Evans, M. (2000). Serving the needs of Visually Impaired Information Seekers in UK Public Libraries. In FLA Council and General Conference. Jerusalem: IFLA. Retrieved from http://www.ifla.org/iv/66/paper/ 111158E.html

18. Farris, C., Trofimovich, P., Segalowitz, N., \& Gatwonton, E. (2008). Air traffic communication in a second language: Implications of cognitive factors for training and assessment: TESOL Quarterly, 42,(3), 397-410.

19. Gallimore, A. (1999). When Special Becomes Every day. Library Technology, 4(1), 1316.

20. Genç, H.\& Gülözer, K. (2013). The effect of cognitive load associated with instructional formats and types of presentation on second language reading comprehension performance. TOJET: The Turkish Online Journal of Educational Technology, 12 (4), 171- 182.

21. Gerber, E. (2003). The benefits of and barrier to computer use for individuals who are visually impaired. Journal of Visual Impairment \& Blindness, 97, 536-550.

22. Gerjets, P., Scheiter, K., \& Catrambone, R. (2004). Designing instructional examples to reduce intrinsic cognitive load: Molar versus modular presentation of solution procedures.

Instructional Science, 32, 33-58.

23. Gerjets, P., Scheiter, K. \& Cierniak, G. (2009). The scientific value of cognitive load 
theory: A research agenda based on the structuralist view of theories. Educational Psychology Review, 21 (1), 4354.

24. Ghanimi, H., Ab Aziz, A., Ahmad, F. (2016). On Modelling Cognitive Load During Reading Task. Malaysian Journal of Human Factors and Ergonomics, 1 (1): $55-61$

25. Giumelli, K. M. (2012). Effect of split attention on grammar learning among children with specific language impairment. Doctor of Philosophy Thesis, Faculty of Education, University of Wollongong. Retrieved from: http://ro.uow.edu.au/theses/3717

26. Gompel, M., Van Bon, W., Schreuder, R.\& Adriaansen, J. (2002). Reading and Spelling Competence of Dutch Children with Low Vision. Journal of Visual Impairment and Blindness, 96: 435-47.

27. Gompel, M., Van Bon, W. \& Schreuder, R. (2004). Reading by Children with Low Vision. Journal of Visual Impairment and Blindness, 98(2): 77-89.

28. Gonzalez Garcia, L. (2004). Assessment of Text Reading Comprehension by Spanishspeaking Blind Persons, British Journal of Visual Impairment, 22: 4-12.

29. Grabe, W. (1991). Current developments in second language reading research. TESOL Quarterly, 25, 375- 406.

30. Gunarhadi, E.\& Sunardi, A. (2017). The use of cooperative integrated reading and composition (circ) method to improve reading comprehension ability of visually impaired students in the 3rd grade of $\mathrm{Sd}$ Slb a Ykab Surakarta, Indonesia. European Journal of Special Education Research, 2(1), 59- 70.

31. Hallahan, D. \& Kauffman, J. (1991). Exceptional children: Introduction to Special Education (5th ed.). United States of America: Prentice-Hall International Inc.

32. Hassan, S. (2017). Using MIBased Activities for Developing EFL Speaking Skills and SelfEfficacy of Preparatory Stage Visually-Impaired Pupils. AlAzhar Faculty of Education Journal, 174 (3), 807- 850.

33. Hill, E., Long, R., Douglas, G., Tobin, M.\& Grimley, M. (2005). Neale Analysis or Reading Ability for readers with low vision: A supplementary manual to aid the assessment of partially sighted pupil's reading using the Neale analysis of reading ability (NARA). University of Birmingham.

34. Hung, H. (2009). Applying cognitive load theory in reading comprehension. Proceedings of the 5th CamTESOL Conference on English Language "The Globalisation of ELT: Emerging 
Directions" Phnom Penh,

Cambodia, 5, 184-196.

Retrieved from

http://www.camtesol.org/Selecte

d_Papers_Vol.5 2009.pdf

35. Jackson, R.M. \& Presley, I. (2012). Audio-Supported

Reading for Students who are Blind or Visually Impaired. Wakefield, MA: National Center on Accessing the General Curriculum. Retrieved from:

http://aem.cast.org/about/public ations/2012/audiosupportedreadi ng-blind-visually-impairedasr.html

36. James, L. (2000). Reading First Teacher Education Network (RFTEN): Teaching teachers strategies for reading success. North Carolina A\& T State University.

37. Jeung, H., Chandler, P. \& Sweller, J. (1997). The role of visual indicators in dual sensory mode instruction. Educational Psychology, 17 (3), 329-343.

38. Jong, T. (2010). Cognitive load theory, educational research, and instructional design: some food for thought. Instructional Science, 38,105-134.

39. Kanokpermpoon, M. (2014). Managing Working Memory in Language Instructions: An Overview of Cognitive Load Theory. Thammasat Review, 16 (2), 93-108.

40. Kapperman, G., \& Sticken, J. (2000). Assistive technology. In
A. J. Koenig \& M. C. Holbrook (Eds), Foundation of education: Volume II. Instructional Strategies for teaching children and youth with visual impairments. New York: AFB press.

41. Kelly, M. (2011). The use of assistive technology by high school students with visual impairments: A second look at the current problem. Journal of Visual Impairment \& Blindness, 105(4), 235-239.

42. Leppink, J., Paas, F., Van Der Vleuten, C., Van Gog, T. \& Van Merrienboer, J. (2013). Development of an instrument for measuring different types of cognitive load. Behavior Research Methods, 45 (4), 1058-1072.

43. Lesnick, J.K. (2006). A mixmethod multi-level randomized evaluation of the implementation and impact of an audio-assisted reading program for struggling readers. Ph.D. Thesis, University of Pennsylvania.

44. Lin, C., \& Yu, Y. (2012). EFL learners' cognitive load of learning vocabulary on mobile phones. Proceedings of the 20th International Conference on Computer in Education, 26-30 November 2012, National Institute of Education, Singapore.

45. Literick (2006). Reading Impairment: VI and dyslexia, compared and contracted. 
Retrieved from http://www.lansyst.co.uk/dyslex ia/reading-impairment.

46. Long, C. (1993). Making Information Available to Partially Sighted and Blind Clients. Electronic Library, 11(6), 373-384.

47. Lõvi, M. (2013). Aspects of Teaching and Learning English as a Foreign Language in the Case of Blind and Visually Impaired Learners in Estonia. M.A. Thesis, University of Tartu, Estonia.

48. Lundeland, N. (2006). Når boka er tung å fordøye: DAISY-bøker, digitale hjelpemidler for elever med lesevansker. When booking is heavy digestive - daisy books, digital aids for students with reading difficulties". Faculty of Education, The University of Oslo.

49. Lundgren, T. (2002). The educational material of the future - for persons with difficulties in reading and writing/dyslexia . Swedish Handicap Institute.

50. Lundh, A. H., \& Johnson, G. M. (2015). The use of digital talking books by people with print disabilities: a literature review. Library Hi Tech, 33(1), 54-64

51. Martin, A.J. (2016). Using Load Reduction Instruction (LRI) to boost motivation and engagement. Leicester, UK: British Psychological Society.
52. Martin, A. \& Evans, P. (2018). Load Reduction Instruction: Exploring a framework that assesses explicit instruction through to independent learning. Teaching and Teacher Education,73. Available at https://www.sciencedirect.com/s cience/article/pii/S0742051X17 $\underline{315172 .}$.

53. Mastropieri, M. A., \& Scruggs, T. E. (1997). Best practices in promoting reading comprehension in students with learning disabilities. Remedial \& Special Education, 18(4), 197-216.

54. Mayer, R. (2008). Learning and instruction (2nd ed.). Upper Saddle River, NJ: Pearson.

55. McLaughlin, R.\& KameiHannan, C. (2018). Paper or Digital Text: Which Reading Medium Is Best for Students with Visual Impairments? Journal of Visual Impairment \& Blindness, 337-350.

56. Meissner, B\& Bogner, F. (2013). Towards Cognitive Load Theory as Guideline for Instructional Design in Science Education. World Journal of Education, 3 (2), 24- 37.

57. Mohammed, Z.\& Omar , R. (2011). Comparison of reading performance between visually impaired and normally sighted students in Malaysia. The British Journal Of Visual Impairment, 29 (3): 196-207. 
58. Moussa-Inaty, J., Ayres, P, \& Sweller, J. (2011). Improving listening skills in English as a Foreign Language by reading rather than listening: A cognitive load perspective. Applied Cognitive Psychology, 26, 391-402.

59. Mousavi, S., Low, R. \& Sweller, J. (1995). Reducing cognitive load by mixing auditory and visual presentation modes. Journal of Educational Psychology, 87 (2), 319-334.

60. Mushome, A.\& Monobe, R. (2013). The Attitude of Lecturers Towards Visually Impaired Students: A Case Study of One of the Universities in the Limpopo Province in South Africa. US-China Education Review A, 3 (2), 108113. ED 540480.

61. Ndung'u, R. (2011). Literacy medium for learners with visual impairments. M.A. Thesis, Faculty of Education Sciences, University of Oslo, Norway.

62. Nes, M. (2007). Appraising and Evaluating the Use of DAISY: A Study of a Reading Aid System. M.A. Thesis, Department of Informatics, University of Oslo.

63. Nkiko, C. et al. (2018). Information Technology and Transcription of Reading Materials for the Visually Impaired Persons in Nigeria. Journal of Education and Learning; (7) 1,42- 52.
64. Nunan, D. (1999). Second language teaching \& learning. Boston: Heinle \& Heinle Publishers.

65. Onuigbo, L.\& Eze, U. (2012). Reading Comprehension Intervention for Students with Visual Impairment: A Comparison of Three Approaches. International Journal of English and Literature (IJEL), 2 (4), 45-58.

66. Paas, F., Tuovinen, J., Tabbers, H., \& Van Gerven, P. (2003). Cognitive load measurement as a means to advance cognitive load theory. Educational Psychologist, 38, 63-71.

67. Pădure, M. (2008). Methods and Techniques for the Access of Persons With Visual Impairments to Handbooks and Textbooks. Revista Informatica Economică nr, 2(46), 125-129.

68. Paris, S. \& Stahl, S. (2005). Children's Reading Comprehension and Assessment. Lawrence Erlbaum Associate. New Jersey London.

69. Partnership for Reading. (2005). Meaning Skills. Background knowledge. Educational center retrieved from: http:// www. nifl.gov / reading profiles / MC _Background_Info.htm.

70. Pollock, E., Chandler, P., \& Sweller, J. (2002). Assimilating complex information. Learning and Instruction, 12, 61-86.

71. Quatraro, A. (2011). ELLVIS English Language Learning for 
Visually Impaired Students, final project report. Italy, Italian Union of the Blind provincial section of Florence

72. Rendulic, D. (2011). Basic Concepts of Information and Communication Technology. Notes: Open Society for Idea Exchange Zagreb, Croatia. Retrieved from http://www.itdesk.info

73. Renk1, A., Hilbert, T., \& Schworm, S. (2009). Examplebased learning in heuristic domains: A cognitive load theory account. Educational Psychology Review, 21, 67-78.

74. Richards, J.C. \& Renandya, W. (2002). Methodology in Language Teaching. Cambridge: Cambridge University Press.

75. Ruffini, M. (2000). Systematic Planning in the Design of an Educational Web Site. Educational Technology, 40 (4).

76. Ryan, S.; Scott, B.; Freeman, H.; Patel, D.(2000). The Virtual University: The internet and resource- based learning. Kogan Page Open and Distance Learning Series.

77. Sadler, C.

Comprehension strategies for middle grade learners content area teachers, Newark, DE: International Reading Association.

78. Shehab, H. (2011). Cognitive load of critical thinking strategies. UNLV Theses,
Dissertations, Professional Papers, and Capstones. 943. https:/digitalscholarship.unlv.ed $\mathrm{u} /$ thesesdissertations/943

79. Si, J., \& Kim, D. (2001). How do instructional sequencing methods affect cognitive load, learning transfer, and learning time? Educational Research, 2,(8), 1362-1372.

80. Spooner, S. (2014). " What Page, Miss?" Enhancing Text Accessibility with DAISY (Digital Accessible Information System). Journal of Visual Impairment \& Blindness, 108(3), 201-211.

81. Stull, A., \& Mayer, R. (2007). Learning by doing versus learning by viewing: Three experimental comparisons of learner-generated versus authorprovided graphic organizers. Journal of Educational Psychology, 99, 808-820.

82. Sweller, J. (2004). Instructional design consequences of an analogy between evolution by natural selection and human cognitive architecture. Instructional Science, 32, 9-31.

83. Sweller, J. (2008). Human Cognitive Architecture. In M. Spector, D. Merrill, J. Van Merrienboer \& M. Driscoll (Eds.), Handbook of research on educational communications and technology (3rd ed., pp. 369-381). New York, NY: Routledge. 
84. Sweller, J. (2010). Element interactivity and intrinsic, extraneous, and germane cognitive load. Educational Psychology Review, 22(2), 123138.

85. Sweller, J., \& Chandler, P. (1994). Why some material is difficult to learn. Cognition and Instruction, 12, 185-233.

86. Sweller, J., Van Merrienboer, J., \& Paas, F. (1998). Cognitive architecture and instructional design. Educational Psychology Review, 10 (3), 251-295.

87. Sydorenko, T. (2010). Modality of input and vocabulary acquisition. Language Learning \& Technology, 14,(2),50-73, Retrieved from http://ltt.msu.edu/vol14num2/sy dorenko.pdf

88. Tank, E., \& Frederiksen, C. (2007). The DAISY standard: entering the global virtual library. Library trends, 55(4), 932-949.

89. Taylor, C. (2013). Cognitive Load Theory - Sometimes Less Is More. i-manager's Journal on School Educational Technology, 9 (1), 61-68.

90. Tindall-Ford, S., Chandler, P. \& Sweller, J. (1997). When two sensory modes are better than one. Journal of Experimental Psychology: Applied, 3 (4), 257287.

91. Van Merrienboer, J., \& Ayres, P. (2005). Research on cognitive load theory and its design implications for e-learning. Educational Technology, Research and Development, 53(3), 5-13.

92. Van Merrienboer, J., Kester, L., \& Paas, F. (2006). Teaching complex rather than simple tasks: Balancing intrinsic and germane load to enhance transfer of learning. Applied Cognitive Psychology, 20, 343352.

93. Van Merrienboer, J., \& Sweller, L. (2005). Cognitive load theory and complex learning: Recent developments and future directions. Educational Psychology Review, 17, 147177.

94. Velázquez, R. (2010). Wearable Assistive Devices for the Blind. In A. Lay-Ekuakille \& S.C. Mukhopadhyay (Eds.), Wearable and Autonomous Biomedical Devices and Systems for Smart Environment: Issues and Characterization, Springer, pp 331-349.

95. Yu, L. (2002). Application of cognitive load theory in English language teaching and learning. Journal of Inner Mongolia Agricultural University (Social Science), 2, 34-37.

96. Zhang, J. (2013). Decreasing Cognitive Load for Learners: Strategy of Web-Based Foreign Language Learning. International Education Studies, 6 (4), 134- 139. 


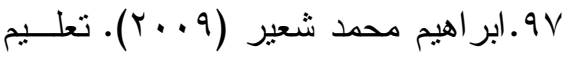

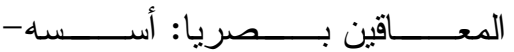

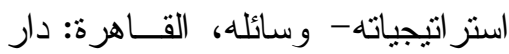

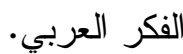

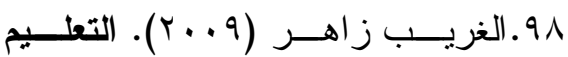

$$
\begin{aligned}
& \text { الإكترترونــي مــن التطبيــق إلــى } \\
& \text { الاحتر اف. القاهرة: عالم الكتب. }
\end{aligned}
$$

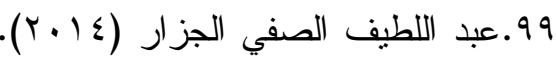

$$
\begin{aligned}
& \text { اتجاهات بحثية في معايير تصميم بيئة }
\end{aligned}
$$

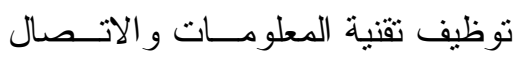

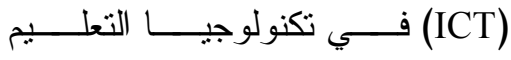

$$
\begin{aligned}
& \text { و التدريب. الندوة الأولى في تطبيقات }
\end{aligned}
$$

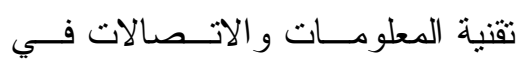

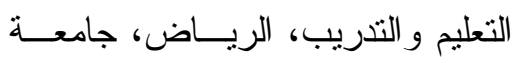

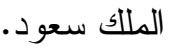

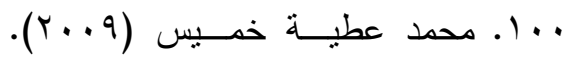

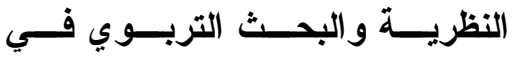

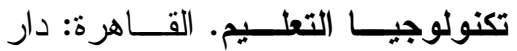

$$
\begin{aligned}
& \text { السحاب للطباعة و النشر و التوزيع. }
\end{aligned}
$$

